\title{
Corticosteroids: way upstream
}

\author{
Therese Riedemann ${ }^{1,2}$, Alexandre V Patchev ${ }^{1}$, Kwangwook Cho², Osborne FX Almeida ${ }^{1 *}$
}

\begin{abstract}
Studies into the mechanisms of corticosteroid action continue to be a rich bed of research, spanning the fields of neuroscience and endocrinology through to immunology and metabolism. However, the vast literature generated, in particular with respect to corticosteroid actions in the brain, tends to be contentious, with some aspects suffering from loose definitions, poorly-defined models, and appropriate dissection kits. Here, rather than presenting a comprehensive review of the subject, we aim to present a critique of key concepts that have emerged over the years so as to stimulate new thoughts in the field by identifying apparent shortcomings. This article will draw on experience and knowledge derived from studies of the neural actions of other steroid hormones, in particular estrogens, not only because there are many parallels but also because 'learning from differences' can be a fruitful approach. The core purpose of this review is to consider the mechanisms through which corticosteroids might act rapidly to alter neural signaling.
\end{abstract}

\section{The protagonists and their roles}

Corticosteroids are the main humoral mediators of stress and their increased secretion in response to adverse stimuli normally results in a cascade of physiological and behavioral homeostatic mechanisms that allow survival and the activation of defense mechanisms against future insults. They facilitate arousal and the appropriate channeling of physiological resources; primarily, corticosteroids act to conserve essential salts, stimulate gluconeogenesis and lipid metabolism, cardiovascular and pulmonary function and erythropoeisis and bone turnover, while inhibiting, among others, reproductive and ingestive behaviors as well as immune responses [1]. Thus, corticosteroids are well suited to serve the fight-or-flight response (first described by Walter B. Cannon in 1915).

Corticosteroids (CS) are primarily produced by the adrenal glands although recent studies suggest that they may also be synthesized in the brain [2,3]. The term 'corticosteroids' embraces two prototypic steroids with distinct biological functions: glucocorticoids (cortisol in most large mammals, corticosterone in rodents and other taxa), named because of their gluconeogenic properties, and mineralocorticoids (primarily aldosterone), named for their role in the regulation of the salt-water balance. Like other steroid hormones, corticosteroids

\footnotetext{
* Correspondence: osa@mpipsykl.mpg.de

${ }^{1}$ Max-Planck-Institute of Psychiatry, Kraepelin Str. 2-10, 80804 Munich, Germany
}

are small, lipophilic molecules (ca. $300 \mathrm{Da}$ ) that are derived from cholesterol. Their physical properties facilitate their passage across the blood brain barrier where they act to maintain brain structure (they are implicated in the regulation of neuronal cell birth, differentiation and apoptosis, as well as dendritic arborization and synaptic function), and integrate a variety of behavioral and physiological processes, including their own secretion. In this respect, they serve as messengers between the periphery and brain, but also between the external and internal environments and the brain.

The hypothalamo-pituitary-adrenal axis embraces the feedforward and feedback neuroendocrine mechanisms that regulate CS production and synthesis (Figure 1). Neural inputs trigger the release of adrenocorticotrophic hormone (ACTH) from the pituitary which, in turn, stimulates adrenocortical synthesis and secretion of CS. Although CS are not stored in a readily-releasable pool, it is estimated that adequate amounts of CS can be released into the bloodstream within minutes of appropriate neural stimuli. Noxious (stressful) stimuli are the primary triggers of neural firing that result in increased CS release. On the other hand, CS are secreted according to strictly-regulated circadian rhythms that are dictated by the central nervous system. More recently, CS have been found to have ultradian rhythmic patterns of release. Such patterns are most likely maintained through dynamic cross-talk between the peripherallyproduced CS and centrally-driven regulatory 


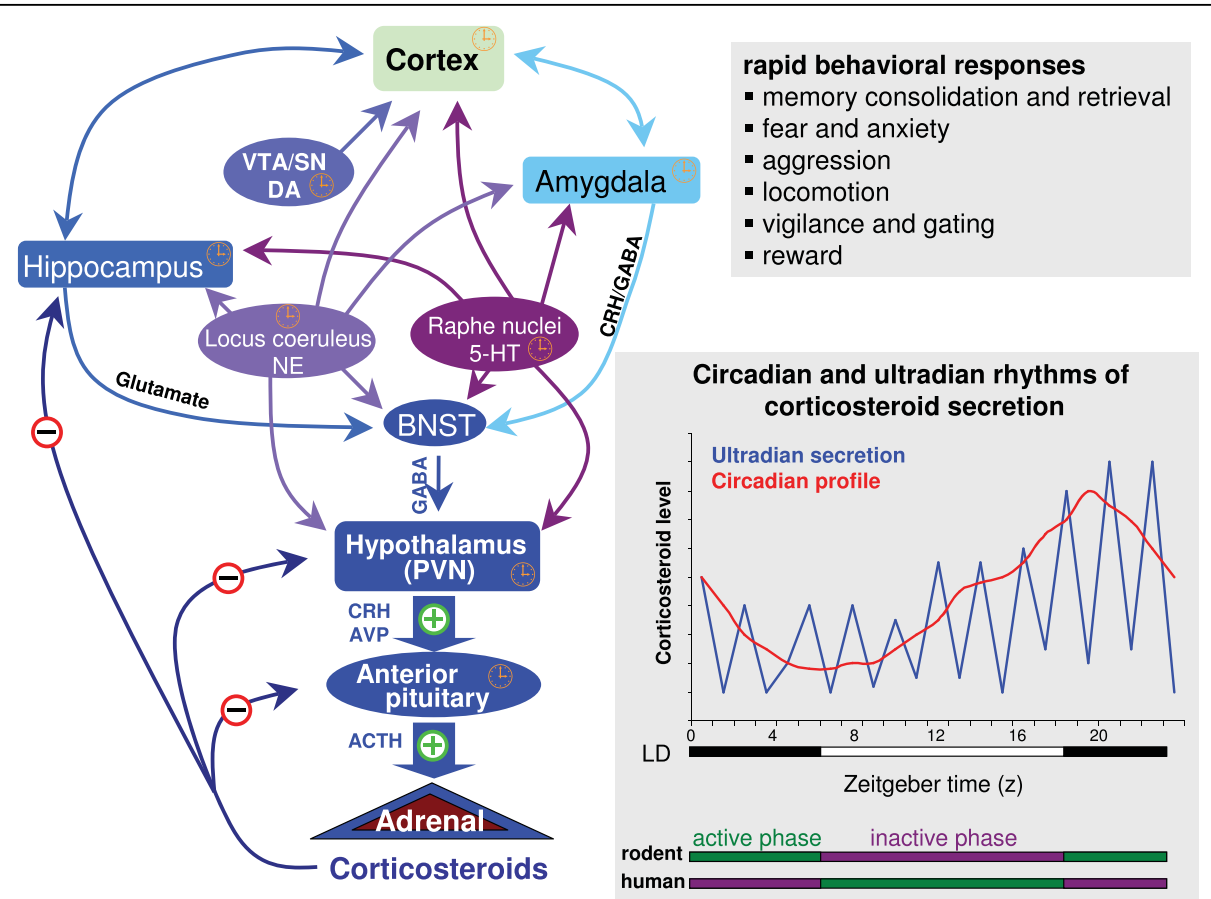

Figure 1 Schematic representation of the hypothalamo-pituitary-adrenal (HPA) axis and its neuronal inputs. Corticotropin-releasing hormone (CRH)- and arginine vasopressin (AVP)-expressing parvocellular neurons in the paraventricular nucleus (PVN) project to pituitary (via the median eminence) where they stimulate adrenocorticotrophic hormone (ACTH) synthesis and secretion, subsequently triggering corticosteroid synthesis and release from the adrenal cortex. Besides acting in the brain to regulate various behaviours, corticosteroids fine-tune the subsequent pattern (amplitude and duration) of corticosteroid secretion; they activate their cognate receptors in the pituitary, hypothalamus and hippocampus and bed nucleus of the stria terminalis (BNST, a relay between the hippocampus/amygdala and the PVN) to restrain, and in the amygdala to enhance, adrenocortical secretion. Monoaminergic transmitters, namely, norepinephrine, serotonin and dopamine released from midbrain nuclei (the locus coeruleus [LC], raphé and ventral tegmental area [VTA] and substantia nigra [SN], respectively) exert modulatory effects on all brain regions involved in the control of the HPA axis. 'Plus' signs (green) indicate positive drive on the HPA axis; 'minus' signs (red) represent sites of corticosteroid negative feedback; 'clock' signs denote neuronal populations known to respond rapidly to corticosteroids. Corticosteroids are secreted rhythmically, displaying ultradian and circadian patterns. The circadian peak coincides with the onset of the daily activity cycle (dark phase in rodents, light phase in humans). While the physiological and behavioural significance of the ultradian rhythms of corticosteroid secretion is still unclear, it is plausible that they serve to dynamically fine-tune the regulation of the HPA axis and thus, to facilitate adaptive processes. $L D$, light-dark cycle.

mechanisms; they are also likely important integrators of normo-physiological functions [4].

Since corticosteroids come on stage within 3-7 minutes of first perception of a stressor [5], they may be considered to be secondary or auxiliary players in comparison to monoamines (in particular, epinephrine and norepinephrine) whose actions are initiated within milliseconds to seconds [6] i.e. corticosteroids are secreted during the first stage of the 'general adaptation syndrome', a concept introduced by Hans Selye in 1946. However, since corticosteroids act against the background of increased monoamine secretion, it is thought that they act to fine-tune the organism's response to stress [7] and to facilitate signal-to-noise discrimination. Moreover, unlike the transient monoamine response, corticosteroids exert sustained actions on cellular activity and behavior, and therefore are essential for ensuring the orchestration of a coordinated adaptive response as well as 'preparedness' of the organism to cope with future challenges.

Although corticosteroids are often thought of in negative terms because of their causative role in diseases such as diabetes, hypertension, osteoporosis and immune suppression, they are essential for adaptation to stress and for maintaining physiological processes. With respect to brain structure and function, corticosteroids play an important role in maintaining hippocampal cell numbers under basal conditions; this is illustrated by robust observations that removal of corticosteroids by extirpation of the adrenal glands results in massive apoptosis, with parallel increases in neurogenesis, within the granule cell population of the hippocampus [8]. On the other hand, stress and elevated levels of glucocorticoids inhibit the generation of new granule neurons [9]. Another aspect that suggests an important role of corticosteroids in normo-physiology is the well-pronounced 
circadian pattern of corticosteroid secretion. These rhythms are robust and bi-directionally tightly coupled to the individual's sleep-activity and feeding cycles, while being entrained and maintained by the daily lightdark cycle.

The magnitude and duration of the humoral response to stress is tightly coupled to the nature (quality, intensity and duration) of the stressor, as well as the context in which it occurs. Depending on context (e.g. the prevailing physiological or psychological state, as well as history of the individual), stressors may trigger excessive corticosteroid secretion over an extended duration; in such cases, the response switches from being an adaptive one into a maladaptive one, marked by transient or chronic pathology. Major depression and cognitive impairment are two conditions that represent the socalled stress-induced disorders of the brain. The first of these seems to reflect a sub-optimal stress-coping strategy and may largely originate from impairments of the mechanisms contributing to the homeostatic negative feedback processes that act to protect the organism against excessive exposure to corticosteroids; frequently, depressed mood is accompanied by impaired cognition and hyperemotionality, indicating that stress impacts on multiple, inter-related neural circuits. A number of human and animal studies have demonstrated the disruptive effects of excessive corticosteroid secretion on cognition [10-12]. There is now strong evidence that the latter involve structural changes, including severe reductions in the dendritic arborization of hippocampal and prefronto-cortical neurons [13-15]. and synaptic loss [16-18]. In addition, recent studies indicate that stress may initiate neurodegenerative processes that increase the risk for severe cognitive deficits such as those seen in dementia of the Alzheimer type [19]. Lastly, chronically elevated levels of corticosteroids interfere with central and pituitary integrators and regulators of the hypothalamo-pituitary-adrenal (HPA) axis, resulting in impaired corticosteroid negative feedback and sustained corticosteroid secretion [20].

\section{The soliloquy we've come to know and love}

Glucocorticoids and mineralocorticoids fulfill their characteristic biological functions through the mediation of glucocorticoid receptors (GR) and mineralocorticoid receptors (MR), respectively. Both of these receptors are present in the brain; while GR are expressed ubiquitously (most strongly in the hippocampus), MR are more discretely distributed (strongly expressed in certain hippocampal subfields and the septum, and moderately expressed in the amygdala and hypothalamic paraventricular nucleus) [21]. The MR has a 7-10-fold greater affinity for corticosterone as compared to the GR [22]. It is thus estimated that the MR is some $80 \%$ occupied under basal conditions, and that the GR only becomes activated when corticosterone levels rise during the daily circadian peak of corticosterone secretion or after stress. Although aldosterone may be synthesized in the brain $[2,3]$, it should be noted that brain MR do not normally 'see' their prototypic endogenous ligand; aldosterone is produced in the periphery at concentrations that are too low to have a direct impact on the brain and in any case, the hormone does not easily cross the blood-brain barrier. On the other hand, it should be mentioned that ligand availability is subject to local regulation through activation/deactivation of cortisol/corticosterone through the actions of $11 \beta$-hydroxysteroid dehydrogenase [23].

The MR and GR belong to the phylogenetically ancient superfamily of nuclear receptors, all of which are transcriptional factors. For the sake of clarity, we will herein refer to nuclear MR and GR as nMR and $n G R$, respectively. Whereas the unliganded $n M R$ is primarily localized in the nucleus, the unoccupied nGR resides in the cytoplasm and only translocates to the nucleus upon ligand activation. This process depends on the dissociation of a host of chaperone and co-chaperone molecules, including heat shock protein 90 (hsp90) as well as on the inclusion of a nuclear translocation signal in the receptor protein [24]. Like other nuclear receptors, $\mathrm{nMR}$ and $\mathrm{nGR}$ are organized according to canonical modules, including a ligand binding domain (LBD), a DNA binding domain (DBD), and two activation functions (AF-1 and AF-2) at their N- and C-terminals, respectively. The various domains share considerable homologies (homology between nMR and nGR: $\sim 57 \%$ in LBD; $\sim 94 \%$ in DBD). Interactions of the DBD with hormone response elements (HRE) in the promoters of specific genes result in the induction or repression of gene transcription and subsequently, changes in the expression of proteins that influence cellular functions. Homologies also exist within the HRE sequence of various nuclear receptors, and receptor recruitment and interactions with specific co-regulator proteins (co-activators/-repressors) may endow these structurally similar receptors with differing specificities and potencies.

\section{Stage props}

Transcriptional and translational effects of corticosteroid receptor activation have been demonstrated using drugs such as actinomycin D and cycloheximide, respectively. On the other hand, demonstration that nGR mediate corticosteroid effects have relied on the use of the antagonist mifepristone (RU 38486, also a potent antagonist of progesterone receptors), while spironolactone or oxoprenoate (RU28318) have been used to demonstrate mediation through nMR. Other potentially useful additions to the pharmacological toolbox for 
studying events mediated by nGR and nMR include established chaperone inhibitors of hsp90 (e.g. cisplatin and geldanamycin; [25]) and of the FK506-binding proteins (e.g. GPI1046; [26]).

\section{Drop scene ${ }^{b}$}

The mode of action of corticosteroids summarized above, i.e. involving gene transcription and translation, may be generalized to all steroid hormone receptors, including those for estrogens. Since nuclear receptors become transcriptionally active upon ligand activation, their actions are, by definition, slow in onset and potentially long-lasting (hours to days, or even months); at best, gene transcription and translation require a minimum of 20-30 minutes (translation takes longer than transcription) [27]. However, steroids have been implicated in the elicitation of a number of 'rapid' or 'fast' physiological and behavioral responses to external stimuli; some examples of fast steroid-mediated responses and the mechanisms thought to underlie their actions are presented in Additional File 1. Historically, the idea that steroids can rapidly alter neuronal excitability and conduction stemmed from work on the actions of sex steroids by Kawakami and Sawyer in 1959 [28] and Woolley and Timiras in 1962 [29].

As a rule, fast responses are considered to be those that occur within the first 20 minutes of increased steroid secretion, i.e. in a much shorter timeframe than that required for effects on gene transcription and protein synthesis. Somewhat erroneously, these fast actions are referred to as 'non-genomic'; in fact, rapidly triggered signaling cascades may ultimately converge in the nucleus to regulate gene transcription and protein synthesis. Distinction between the 'fast' and 'slow' actions of steroid hormones is more of mechanistic than of behavioral or physiological importance, since the latter are the integrated manifestations of sequential events. Viewed from this perspective, the rapid actions of steroids may be considered as 'primers' of the substrates responsible for the manifestation of transcriptional events triggered by nuclear receptors; kinase cascades activated during early phases of steroid action and which lead to the phosphorylation of regulatory sites of nuclear receptors [30-32] are a good example of such priming functions.

Many of the changes in behavior and brain physiology that are listed in Additional File 1 reflect rapid responses of the hippocampus to steroid hormones. For example, corticosteroids have been consistently shown to influence cognition and their effects are thought to result from their ability to directly or indirectly alter the excitability of hippocampal neurons. The hippocampus has been extensively studied for a number of pragmatic reasons. The input-output connections of the different hippocampal subfields are well defined, making their electrophysiological study convenient. Of all brain areas, the hippocampus has been best studied in the context of long-term potentiation (LTP) and long-term depression (LTD), the electrophysiological correlates of learning and memory, functions in which the hippocampus is strongly implicated [[33-35]; see Figure 2 and Additional File 2]. The hippocampus also serves as an important homeostatic regulator of the HPA axis upon which it exerts a strong negative drive [36,37] through the mediation of nMR and nGR [38].

Although the attention paid to the hippocampus is justifiable because of its role in the regulation of many behavioral and physiological processes, it should be remembered that it constitutes only part of a complex neuronal network that underpins physiology and behavior in normal and pathological states. For example, although the hippocampus plays an important role in the regulation of the HPA axis, it should be noted that other brain areas such as the prefrontal cortex [39], amygdala and bed nucleus of the stria terminalis, under the modulatory influence of monoamines from the hindbrain [40], contribute to the control of corticosteroid secretion; all these areas have reciprocal connections with the hippocampus and express nGR.

Several studies have begun to define how corticosteroids and other steroids act on different brain structures to produce integrated and adaptive behavioral and physiological responses, e.g. the prefrontal and orbito-frontal cortices (executive functions, including attention, behavioral flexibility, declarative memory, decision making $[41,13,14,42]$ ), thalamus (processing and gating of sensory input [43], amygdala (evaluation of emotional load of sensory input and regulation of fear [44], ventral striatum (motivation and reward [45] and decision-making [42]), and the cerebellum (learning of motor tasks [46]. Of these, the amygdala, involved in the control of fear, aggression and cognition (see Additional File 1), has been the most intensively studied. Interesting work by Roozendaal and colleagues has demonstrated a crosstalk between rapid GC and noradrenergic signaling in contextual memory consolidation [44,47] and suggests that endocannabinoids are key mediators of this crosstalk [48].

\section{Putative membrane receptors - pirates with legs to stand on?}

The message that emerges from the previous section is that nuclear receptors, acting as transcriptional factors, are unlikely to mediate rapid actions of the sort listed in Additional File 1. Nevertheless, the identity of the molecular entity that allows rapid transduction of steroid signals remains elusive. Interestingly, some of the fast responses to corticosteroids are reportedly attenuated in 


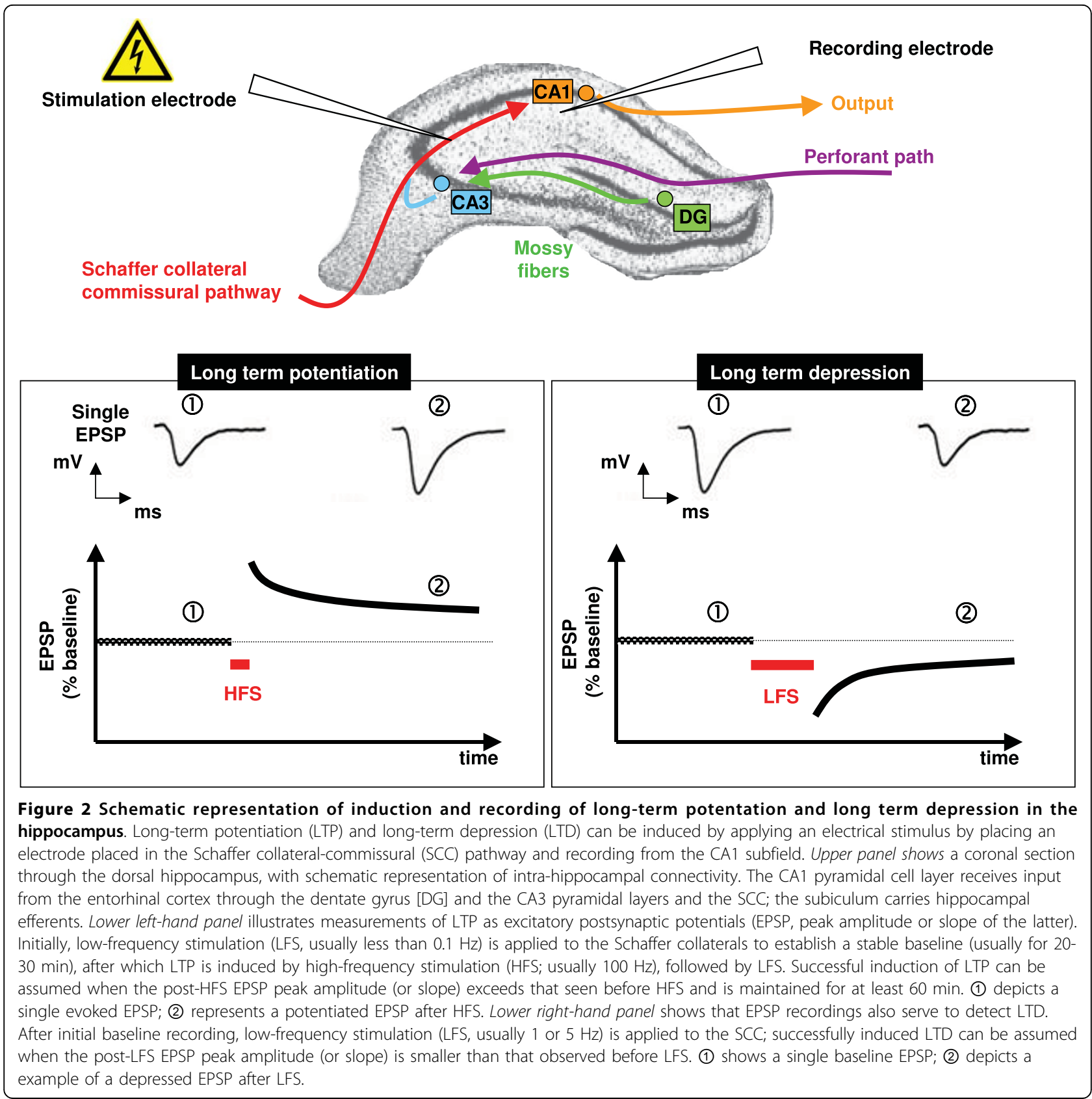

the presence of pharmacological antagonists of nGR (RU 38486 [49] or nMR (spironolactone [50,51]). These findings suggest certain homologies between the classical nuclear receptors and the putative receptors mediating the rapid actions of these steroids. Nevertheless, the existence of another class of receptors, with distinct chemistries and cellular localizations, and that are not sensitive to the above-named antagonists, cannot be dismissed.

Several mechanisms that may account for membranemediated transduction of the rapid actions of estradiol have been proposed (see Figure 3). Substantial evidence supports the view that classical nuclear estrogen receptors (nER of which there are two isoforms, ER $\alpha$ and ER $\beta$ ) are integrated into, or in close proximity of, the cell membrane. One hypothesis is that palmitoylation facilitates the interaction of these receptors with caveolins, a family of proteins that associate with cholesterol and sphingolipids to form caveolae within the plasma membrane and which are implicated in signal transduction. While some authors describe protein-protein interactions of such membrane-associated nER with other membrane proteins as a mechanism to explain rapid estrogen signaling [52-54], others propose mediation by a membrane- 


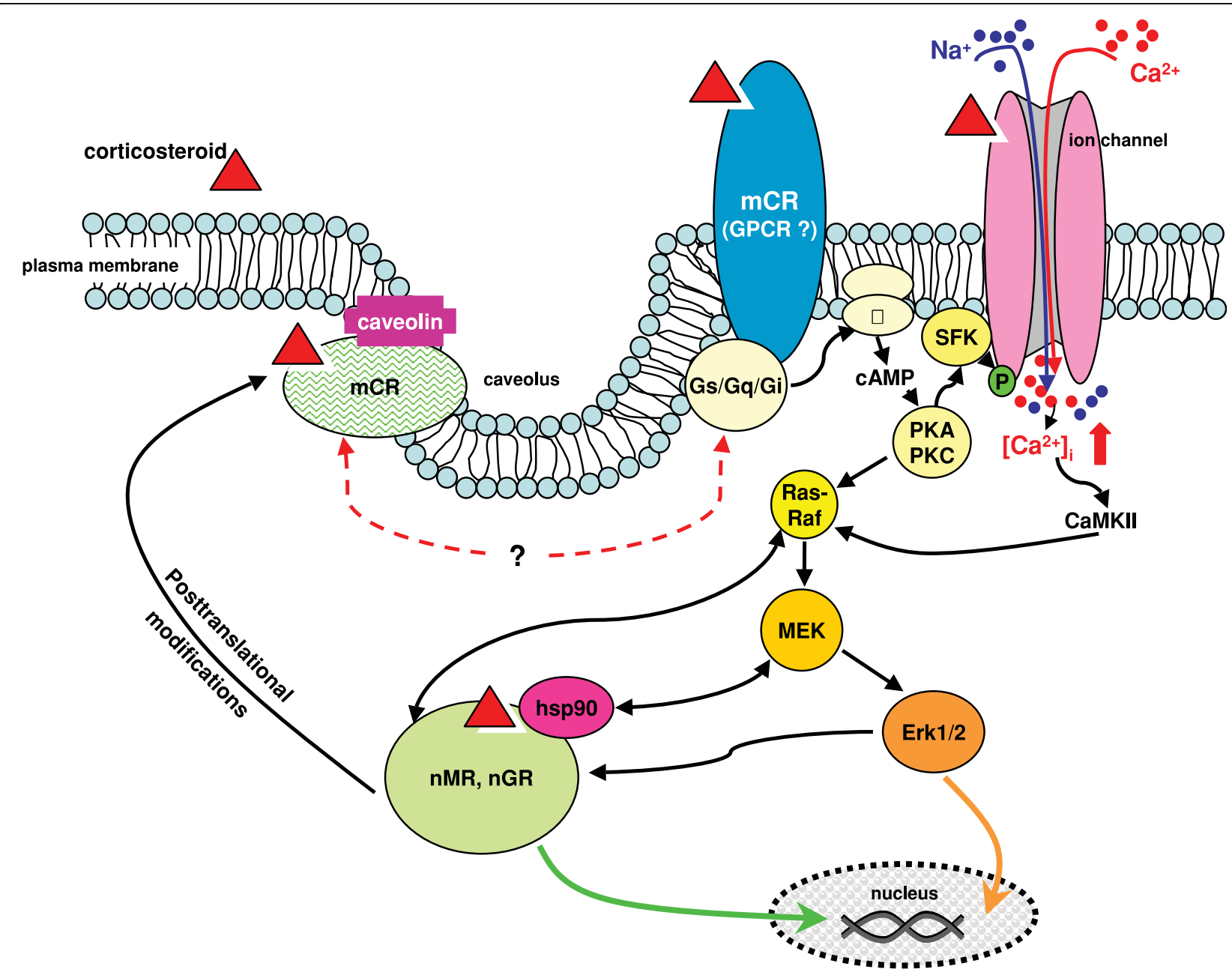

Figure 3 Schematic representation of corticosteroid-triggered multiple tentative rapidly influencing neuronal function. Corticosteroids are represented by red triangles. Nuclear GR ( $\mathrm{nGR}$ ) interact with caveolins [cf. [81]]; the interaction probably depends on posttranslational modifications of nGR to yield so-called membrane corticosteroid receptors (mCR). Alternatively, CS-initiated intracellular signaling cascades may result from corticosteroid binding to proteins embedded in the plasma membrane, e.g. G-protein-coupled receptors (GPCR) [75] which, upon activation, activate protein kinase A (PKA) and protein kinase C (PKC) in turn. Other evidence points to membrane-bound corticosteroid binding proteins that interact with members of the src family of kinases (SFK) to activate the mitogen-activated protein kinase (MAPK) pathway and/or modulate the activity of other membrane-associated proteins, e.g. NMDA receptors and other ion channels with potential steroid binding sites $[76,85,86,222]$. Under basal conditions, $\mathrm{nGR}$ are tethered in the cytoplasm in the form of a protein complex that includes the chaperone heat shock protein 90 (hsp90) which itself may directly interact with Src kinases and the MAPK kinase, MEK [cf. [83]]. Additionally, direct interactions between the nGR and Ras which may be functionally relevant have been described [84]. Finally, MAPK-mediated phsophorylation of nGR may influence the transcriptional activity of nGR [32]. Thus, corticosteroid actions at the plasma membrane can converge and prime or potentiate hormonal actions on gene transcription.

bound ER (mER) that is coupled to a $G \alpha_{\mathrm{q}}$ protein. Evidence for the latter includes the observation that estradiol induces activation of the phospholipase $\mathrm{C}$ - protein kinase A (PLC-PKC-PKA) pathway in nER knockdown mice [55]. The same investigators demonstrated rapid electrophysiological effects of STX, a diphenylacrylamide-based selective estrogen receptor modulator, in nER knockout animals; STX, which does not bind to either isoform of the $\mathrm{nER}$, proved to be more potent than estradiol in their in vitro and in vivo test systems $[55,56]$.
While no mER has been cloned and characterized to date, GPR 30, an orphan G protein-coupled receptor (GPCR), has been identified as a potential transducer of estrogen signals that originate at the cell membrane $[57,58]$. GPR 30 was shown to display similar structural characteristics to other membrane receptors [57], but was nevertheless viewed with a certain amount of skepticism. For example, the nER antagonist ICI 182,780 exerts agonistic effects on this receptor [59] and neurons from GPR 30 knockout mice still display rapid responses to 
estradiol [60], the latter finding suggesting that GPR 30 may co-exist alongside (an)other mER with unique pharmacological properties. Notably, in an extension of their earlier work, Revankar et al. [61] exploited chemical biology to explore the subcellular localization of GPR 30 and its signaling potential; on the basis of observations in 4 cancer cell lines, they discarded the notion that sufficient GPR 30 is localized at the plasma membrane and rather suggested that GPR 30 localized in the endoplasmic reticulum serves as an intracellular transmembrane receptor for estrogen

Interestingly, Toran-Allerand and colleagues [62,63] described a high affinity $\left(\mathrm{K}_{\mathrm{D}}\right.$ for estradiol: $\left.1.6 \mathrm{nM}\right)$ caveolin-associated protein in the plasma membranes of neonatal (but not adult) neocortical and uterine tissues. This so-called ER-X seems to come closer to meeting the expectations of a distinct $\mathrm{mER}$ insofar that it cannot be blocked by ICI 182,780 [62]; moreover, these authors found that experimentally-induced ischemic stroke in adult animals is accompanied by an upregulation of ER$\mathrm{X}$ in the brain, suggesting that the ER-X mediates the neuroprotective actions ascribed to estrogens.

It is tempting to hypothesize, that the mediators of rapid corticosteroid effects may share similar basic properties and mechanisms with the proposed membraneassociated estrogen receptors. The existence of a membrane-bound receptor for corticosteroids (herein referred to as $\mathrm{mCR}$ ) was postulated by Willmer in 1961 [64]. Willmer's suggestion that steroid hormones interdigitate with, and alter the permeability of, lipids in the plasma membrane, lost currency as evidence that steroids bind to intracellular proteins (nuclear receptors) and stimulate protein synthesis began to accumulate from 1961 onwards $[65,66]$. However, in 1974 Satre and Vignais described corticosterone binding to mitochondrial preparations from the adrenal and kidney [67], a finding that eventually extended to other cell types [68]. A series of authors provided evidence for membranebound steroid recognition sites in the brain [69-71]; among these, Towle and Sze demonstrated specific corticosterone binding to plasma membrane preparations from rat brain synapses [72]. These membrane binding sites had a relatively high affinity for corticosterone $\left(K_{D}\right.$ $10^{-7} \mathrm{M}$ vs. $10^{-9} \mathrm{M}$ in the case of cytosolic binding sites) and treatment with phospholipase A2 or phospholipase $\mathrm{C}$ led to complete dissociation of membrane-bound corticosterone. Similarly, Orchinik et al. described the presence of $\mathrm{mCR}$ in brain synaptosomal fractions obtained from the amphibian Taricha granulosa (rough-skinned newt) [69]. These receptors showed pharmacological specificity for corticosterone and cortisol $\left(K_{D} 10^{-9} M\right)$, and lesser affinities for aldosterone and other natural and synthetic steroids (such as dexamethasone and RU 38486). Importantly, Orchinik et al. reported a linear relationship between the potencies of various compounds (corticosterone being the most potent) in inhibiting male reproductive behavior (inhibition by corticosterone within 8 minutes of application) and their ability to bind the putative $\mathrm{mCR}$ [69]. In subsequent studies, these authors described similar neuronal $\mathrm{mCR}$ in mammalian [73] and bird [74] brains and suggested a role for guanine nucleotide-binding proteins in the formation of a ternary complex of corticosterone and the putative neuronal $\mathrm{mCR}$, i.e. the $\mathrm{mCR}$ appears to be coupled to $\mathrm{G}$ proteins [75]. Additional evidence for the existence of a mCR was eventually provided by Orchinik's colleagues who solubilized and partially purified membrane-bound corticosterone binding sites from the amphibian brain [76]; the assumed $\mathrm{MCR}$ had a molecular weight of about $63 \mathrm{kDa}$, as compared to 97 $\mathrm{kDa}$ and $110 \mathrm{kDa}$ in the case of the $\mathrm{nGR}$ and $\mathrm{nMR}$, respectively. More recently, studies by Johnson et al. [77] provided anatomical evidence for the existence of nGR within the postsynaptic density of neurons in the rodent amygdala. At present it is unclear as to whether there are any homologies between the $\mathrm{mCR}$ and either the $n G R$ or $n M R$.

Ultrastructural studies with an antibody against purified rat nGR revealed immunoreactivity associated with the plasma membrane of rat hippocampal and hypothalamic neurons [78]. Notably, membrane-associated immunoreactive $\mathrm{nGR}$ sites were observed in or near membranes covering the dendrites and somata of pyramidal neurons; nGR immunoreactivity was also seen in the vicinity of the Golgi complex. With regard to the plasma membrane, Liposits and Bohn [78] noted that nGR immunoreactivity was associated with coated vesicles which, together with their localization along the membrane, suggested that nGR might either be transported and inserted into the plasma membrane, or coupled to mediators of transduced signals. In this respect, parallels may be drawn with what was reported above with respect to the membrane-bound mediators of estrogen actions. Palmitoylation of the nER has been suggested as a mechanism that facilitates integration of the nuclear receptor into (or the proximity of) the cell membrane, thus providing access to BSA-conjugated steroids and interactions of the receptor with membrane-associated signaling proteins [79]. While it remains to be shown that classical corticosteroid receptors can be palmitoylated and trafficked to the plasma membrane, recent studies have identified a highly conserved 9-amino acid motif in the ligand binding domain of estrogen, progesterone, androgen and glucocorticoid receptors that could serve as a substrate for palmitoylation [80]; these observations suggest that palmitoylation may be a general mechanism that allows nuclear receptors to double up as bona fide membrane receptors. 
Supporting the plausibility of this view, Matthews et al. have shown that nGR interacts with caveolin [81].

Many unliganded nuclear receptors (e.g. nGR), are tethered in the cytoplasm through their association with chaperone proteins such as heat shock protein 90 (hsp90); this complex is dissociated upon arrival of the ligand [24]. Interestingly, hsp90 is known to interact with src kinase [82], a membrane-proximal kinase thought to mediate the rapid activation of the MAPK pathway by corticosteroids. In addition, hsp90 interactions with MEK2, another kinase upstream of MAPK, has been shown to mediate MAPK pathway activation by estradiol [83]. In fact, nGR itself reportedly interacts with Raf-1, a downstream effector of Ras, and upstream regulator of the MAPK pathway [84].

Receptors for several neurotransmitters (some of which are ion channels) have been shown to bind CS $[76,85,86]$. Although it remains unclear as to whether these interactions serve as a conduit of the rapid actions of CS, the latter seems plausible given the evidence that neurosteroids can modulate chloride flux and thereby, neuronal excitability, by binding to an allosteric site on the $\mathrm{GABA}_{\mathrm{A}}$ receptor [87].

In summary, there is growing support for the view that CS can initiate signaling at the plasma membrane through one or more of the following mediatory mechanisms: (i) G protein-coupled membrane-bound CS receptors, (ii) steroid modulatory sites on plasmabound neurotransmitter receptors, (iii) interactions between cytoplasmic CS receptors and kinase familyinteracting chaperone molecules, and/or (iv) palmitoylation. Elucidation of the mechanisms underlying the rapid actions of CS will require a stepwise analysis of the contributions of each member of this 'interactome' a major challenge.

\section{From the sightlines - peeping on a rapidly changing stage}

This section will focus on the cellular endpoints that can be used to support the view that corticosteroids rapidly influence neuronal activity, focusing on alterations in membrane excitability and signaling cascades that originate at or close to the plasma membrane. However, attempts to summarize the existing literature are confronted with the fact that the results derive from disparate protocols and experimental models in different laboratories. For example, a wide range of corticosteroid doses and exposure times have been applied to studying synaptic transmission in either rat or mouse dissociated hippocampal neurons or hippocampal slices. We will, however, first consider early studies on hypothalamic neurons by Kasai and colleagues and Saphier and Feldman, using in vitro ionotophoresis. Kasai and colleagues showed that cortisol excited tuberoinfundibular neurons in the paraventricular nucleus (PVN) which project to the median eminence from where their neurosecretory products reach the anterior pituitary; however, these authors also reported inhibitory effects of cortisol in the PVN, suggesting this to result from inhibition of noradrenergic inputs [88-90]. Saphier and Feldman, observed a significant reduction in the spontaneous firing rates of similar hypothalamic neurons after the application of corticosterone [91,92]; these changes had a rapid onset and were maintained even after iontophoresis of the hormone was stopped. Further, they reported on a subset of neurons whose activity was not altered by corticosterone; glutamate-induced excitation of these neurons was however suppressed in the presence of corticosterone.

Together, the studies described above represent a hypothalamic electrophysiological correlate of the negative feedback control of adrenocortical secretion, and illustrate that corticosteroids can elicit different responses from different brain areas or neuronal populations within an anatomical region or specific neuronal phenotypes within a given subfield; moreover, the responses depend on neural inputs to the particular set of neurons under investigation [91,93]. Given the suggested importance of the hippocampus in mediating glucocorticoid negative feedback (see above), it is surprising that Barak [94] failed to observe any changes in the activity of hippocampal neurons upon applying corticosterone. As will become evident below, despite a large number of studies that focussed on the CA1 subfield of the hippocampus, it is difficult to compile a consensus view of how corticosteroids impact on the activity of this region.

Examining spike accommodation in hippocampal neurons, Vidal et al. reported that corticosterone $(1 \mu \mathrm{M})$ decreases spike numbers [95], whereas Joëls and de Kloet [96] and Beck et al. [97], using $1 \mathrm{nM}$, observed the steroid to increase spike numbers and decrease the after-hyperpolarisation (AHP) amplitude; these effects were abolished in the presence of spironolactone (nMR antagonist). Importantly, $30 \mathrm{nM}$ of corticosterone, which activates nGR (as well as nMR), decreased spike numbers and increased AHP amplitude, leading the authors to conclude that the bifurcating actions of low and high doses of corticosterone reflect the activation of nMR and $n G R$, respectively [96]. Further, given the gradual rise in corticosterone levels upon arrival of a stimulus (e.g. stress), they proposed a concentration-dependent biphasic cellular response to corticosterone, i.e. an initial increase in neuronal excitability, followed by suppression of neuronal excitability. Similar findings were reported earlier by Rey et al. (effects observed between 0.2 and $10 \mathrm{nM}$ corticosterone; peak increase in spike amplitude at $2 \mathrm{nM}$ corticosterone) [98]. 
Given that the amplitude of the AHP is determined by $\mathrm{Ca}^{2+}$ and $\mathrm{Ca}^{2+}$-dependent $\mathrm{K}^{+}$transients $[99,100]$, it is interesting that Landfield and colleagues reported that high doses of the synthetic GR agonist RU28362 $(7 \mu \mathrm{M})$ enhance the amplitudes of voltage-dependent calcium channel (VDCC)- mediated $\mathrm{Ca}^{2+}$ spikes in a protein synthesis-dependent manner [101]. In contrast, Tian et al. suggested that the increase in the slow after-hyperpolarization amplitude seen after exposure to high doses of corticosterone may involve cAMP-dependent phosphorylation and $\mathrm{Ca}^{2+}$-activated $\mathrm{K}^{+}$channels [102]: dexamethasone $(1 \mu \mathrm{M})$, a synthetic glucocorticoid with high selectivity for the nGR, blocked PKA-mediated inhibition of $\mathrm{Ca}^{2+}$-activated $\mathrm{K}^{+}$channels without influencing VDCC-mediated $\mathrm{Ca}^{2+}$ currents in a mouse pituitary cell line (AtT20). It should be noted that Tian et al. treated their cells with dexamethasone for $2 \mathrm{~h}$ and that these effects required de novo protein synthesis for their manifestation [102,103]. Because activation of NMDA receptors results in an influx of $\mathrm{Ca}^{2+}$ and, as mentioned above, $\mathrm{Ca}^{2+}$ determines the AHP amplitude [99], corticosteroid-NMDA receptor interactions have been analyzed in a number of studies using electrophysiological recordings as the endpoint. For example, Wiegert et al. showed that exposure of mouse hippocampal slices to corticosterone $(100 \mathrm{nM})$ for 20 min resulted in NMDA receptor-mediated suppression of primed-burst potentiation and synaptic potentiation [104] (induced by stimulation at $10 \mathrm{~Hz}$, in contrast to the more commonly-used $100 \mathrm{~Hz}$ LTP regimen). In contrast, theta-burst potentiation (see Additional File 2 for information on different stimulation protocols), which requires activation of both NMDA receptors and voltage-dependent $\mathrm{Ca}^{2+}$-channels was not affected by corticosterone treatment. The same authors also described a role for L-type $\mathrm{Ca}^{2+}$ channels in the synaptic actions of corticosterone [105]. In the context of the question of whether corticosterone can rapidly alter synaptic function, it is important to note, however, that Wiegert et al. [104] and Chameau et al. [105] made their electrophysiological recordings between 1 and $6 \mathrm{~h}$ after initial exposure to the steroid. On the other hand, Chameau et al. [105] found by quantitative PCR that corticosterone did not change the mRNA expression of the pore-forming $\mathrm{Ca}_{\mathrm{v}} 1$ subunit of the L-type $\mathrm{Ca}^{2+}$ channel, and ruled out transcriptional mechanisms in the effects they observed.

Wiegert et al. [104] showed that RU 38486 blocks corticosterone-induced impairments of synaptic plasticity, implying mediation of the effects by nGR. A similar conclusion was drawn from their previous work on $G R^{\mathrm{dim} / \mathrm{dim}}$ mice, a strain carrying a point mutation of the DNA binding domain of the nGR which precludes transcriptional effects; briefly corticosterone did not influence VDCC-mediated $\mathrm{Ca}^{2+}$ currents in hippocampal slices from $\mathrm{GR}^{\mathrm{dim} / \mathrm{dim}}$ mice [106]. To address the question of how glucocorticoids enhance $\mathrm{Ca}^{2+}$ currents on the one hand, and reduce synaptic efficacy on the other, Joëls' laboratory examined synaptic efficacy 1-4 h after a brief exposure to corticosterone $(1 \mu \mathrm{M}$ CORT for 20 min) [107]. Their investigations revealed that synaptic transmission was potentiated when VDCCs were activated, and impaired only when NMDA receptors were activated; moreover, they found that these effects were RU 38486-sensitive, indicating their mediation by nGR. Together, these observations point to the importance of considering all of the individual components that contribute to the overall response in field recordings. In this respect, it is worth recalling that the magnitude of LTP and LTD is a function of the number of AMPA receptors that are present at the synaptic surface (see Additional File 2). Miniature excitatory postsynaptic currents (mEPSCs, which represent the spontaneous release of neurotransmitter quanta from presynaptic terminals) are mediated by AMPA receptors and changes in the mEPSC amplitude represent postsynaptic changes in AMPA receptor properties and/or numbers. Indeed, Martin et al. observed that corticosterone increases the amplitude (but not frequency) of miniature excitatory postsynaptic currents and demonstrated that corticosterone increases trafficking of the GluR1 and GluR2 subunits of the AMPA receptor to the synaptic surface, apparently through an nGR-dependent mechanism [108]. This last study is in good agreement with that by Karst and Joëls, who also reported nGR-mediated increases in mEPSC amplitude [109].

Despite the overwhelming amount of data implying a role for nGR and/or nMR in mediating the effects of corticosterone on synaptic transmission, other evidence indicates that the rapid actions of corticosterone are mediated by $\mathrm{mCR}$. For example, corticosterone was shown to dose-dependently $(0.1,1,10,100 \mu \mathrm{M})$ inhibit inward NMDA receptor-mediated currents, within seconds, in primary hippocampal cultures [110]. This effect faded upon wash-out of the hormone and was not reversible with RU 38486; assuming that RU 38486 binds specifically to $\mathrm{nGR}$, the latter finding precludes mediation through nGR. The latter interpretation is supported by the finding that the effects of corticosterone were reproducible with membrane-impermeable BSAconjugated corticosterone. Results from Takahashi et al. also dismissed a mediatory role for nGR or nMR in the mediation of corticosterone effects; however, they reported that the steroid prolongs the elevation of NMDAR-mediated $\mathrm{Ca}^{2+}$ influx in dissociated hippocampal neurons independently of VDCC and mobilization of intracellular $\mathrm{Ca}^{2+}$ stores [111]. In contrast, other authors reported that corticosterone and BSA-corticosterone (30 min) inhibit the peak amplitude of NMDA 
receptor-mediated $\mathrm{Ca}^{2+}$ currents in the CA1 subfield of the mouse hippocampus [93], that bath application of corticosterone to hippocampal slices inhibits VDCCmediated $\mathrm{Ca}^{2+}$ currents within minutes [112], and that corticosterone increases synaptosomal uptake of $\mathrm{Ca}^{2+}$ upon $\mathrm{K}^{+}$-induced depolarization [113].

At this stage, it is important to note that some of the discrepant reports on corticosterone-induced changes in NMDAR-mediated $\mathrm{Ca}^{2+}$ currents may reflect the different durations of exposure to the steroid used by different groups. In fact, Wiegert et al. defined a narrow time window (10 min before high frequency stimulation) during which corticosterone facilitates synaptic potentiation; longer bath applications of the hormone were found to impair synaptic potentiation [114].

Most of the evidence reviewed above presumes postsynaptic sites of corticosterone action. New studies of CA1 neurons also report changes in the frequency of mEPSCs, thus implying presynaptic sites of action. Thus, Karst et al. [50] and Olijslagers et al. [51] showed that corticosterone increases the frequency of AMPA receptor-mediated mEPSCs. Both studies show that application of BSA-conjugated corticosterone produced similar effects to those obtained with corticosterone, and interestingly, that de novo protein synthesis was not essential for their manifestation. Together, these results hint at the involvement of receptors other than nGR and nMR; nevertheless, nMR antagonism by spironolactone resulted in a blockade of the corticosteroneinduced increases in mEPSC frequency. [50,51] [but see [114]]. On the other hand, since RU 28362, a synthetic nGR agonist, did not reproduce the effects of corticosterone, and because the effects were not antagonizable with RU 38486, Karst et al. [50] and Olijslagers et al. [51] proposed that the putative $\mathrm{mCR}$ might share identity with the nMR. The latter suggestion is supported by experiments in mice with targeted mutations of nGR and nMR [50,106] and work by Groc et al. [115]. Using dissociated hippocampal cells to visualize AMPA receptor trafficking, the latter authors observed increased synaptic surface expression of GluR2 subunits of the AMPA receptor within minutes of exposure to corticosterone, BSA-conjugated corticosterone or aldosterone (the prototypic nMR agonist).

Related to the electrophysiological measures summarized in the last few paragraphs, Olijslagers et al. demonstrated that activation of the MAP kinase ERK1/2 is crucial for the corticosterone-induced increase in mEPSC frequency [51]. Interestingly, their experiments showed non-dependence on postsynaptic G protein activity on mEPSC frequency. Rather, by using the $\mathrm{H}$ Ras G12V strain of mouse which displays strong presynaptic activation of ERK1/2 due to constitutively high expression of the $\mathrm{H}$-Ras transgene, they suggested that the actions of corticosterone are initiated at presynaptic sites, increasing the probability of presynaptic neurotransmitter release [50,51]. Moreover, in agreement with other studies [111], Olijslagers et al., reported that intracellular $\mathrm{Ca}^{2+}$ stores do not influence mEPSC frequency upon exposure to corticosterone [51]. Lastly, it should be noted that although the involvement of $\mathrm{G}$ proteins in corticosterone-induced changes in mEPSC frequency were excluded [51], direct infusion of GDP $\beta$ S into the postsynaptic cell prevented the decrease of the peak amplitude of $\mathrm{I}_{\mathrm{A}}$ currents (postsynaptic $\mathrm{K}^{+}$conductance) by corticosterone [51]; this finding points to mediation through a postsynaptic mCR-dependent mechanism.

A number of studies suggest a role of $G$ proteins in the mediation of the rapid actions of corticosterone. For example, ffrench-Mullen showed that the inhibition of $\mathrm{Ca}^{2+}$ currents by cortisol in guinea pig CA1 neurons depends on pertussis toxin-sensitive G-proteins [112]. The same author also showed that the effects of cortisol are significantly diminished in the presence of PKC inhibitors (BIS and PKCI 19-31), and ruled out a role for PKA in the mediation of the actions of cortisol [112]. Similarly, Chen and Qiu showed that corticosterone rapidly inhibits VDCC-mediated $\mathrm{Ca}^{2+}$ currents in a phaeochromocytoma cell line of neural origin (PC12 cells), and that inhibition of $\mathrm{G}$ proteins by application of either pertussis toxin or GDP $\beta S$ significantly attenuates the ability of either corticosterone or BSA-corticosterone to stimulate the influx of $\mathrm{Ca}^{2+}$ [116]. They also demonstrated that activation of PKC with phorbol 12-myristate 13-acetate results in an inhibition of $\mathrm{Ca}^{2+}$ entry though VDCC after depolarization with $\mathrm{K}^{+}$, and that the application of corticosterone activates PKC within 5-15 minutes. Lastly, like Qi et al. [117] who obtained similar results in primary hippocampal neurons, Chen and Qiu [116] showed that both, corticosterone and BSA-conjugated corticosterone trigger the activation of $\mathrm{PKC}$ and a series of MAP kinases (ERK1/2, p38MAPK and c-Jun) in $\mathrm{PC}-12$ cells; maximum kinase activation occurred within $15 \mathrm{~min}$ of application of the hormone and the effects could not be attenuated by RU 38486 .

\section{Reality}

Blood (and brain) corticosteroid levels rise and fall in a pulsatile manner under basal (unstimulated) conditions, and the circadian and stress-induced rises in corticosterone secretion occur gradually, taking minutes or even hours to reach peak levels. This raises the question of whether corticosteroid levels above a certain threshold have an impact on physiology and behavior and provokes curiosity about the mechanisms that could underpin the rapid biological actions of corticosteroids. Original interest in the fast actions of corticosteroids was awakened by attempts to understand the 'fast' and 
'slow' negative feedback actions of corticosteroids at the level of the pituitary and the brain. Pioneering research by Mary Dallman used ingenious experimental designs which eventually provided evidence for the rapid actions of corticosteroids in reducing their own secretion [118] and, as already mentioned, the search for electrophysiological correlates was pursued in the hypothalamus in parallel. Today, predominantly based on work from the laboratories of Stafford Lightman and colleagues [4], it would appear that the ultradian rhythmic secretion of relatively high-amplitude corticosterone may serve to ensure low levels of adrenocortical activity during the organism's resting phases; these brief pulses presumably act rapidly to suppress brain-pituitary drive of adrenal secretion.

At the behavioral level, Orchinik et al. [69] elegantly demonstrated the potency of corticosterone in inhibiting male reproductive behaviour in newts, within $8 \mathrm{~min}$ of application. In mammals, Jozsef Haller and colleagues have shown that corticosterone injections elicit aggressive and anxiety-related behavior (latency of $7 \mathrm{~min}$ ) in rats whose endogenous adrenocortical activity is suppressed by inhibition of $11 \beta$-hydroxylase activity with metyrapone [119-121]. Several authors have also described the ability of corticosterone to rapidly alter locomotor behavior in rodents; for example, acute systemic injections of corticosterone to rats (placed in a novel environment) were shown to stimulate locomotion within 7.5 minutes of administration [122].

Rhythms in the secretion of corticosteroids and other neuromodulatory molecules can influence experimental outcomes, even in in vitro settings. For instance, $\mathrm{Ca}^{2+}$ currents into hippocampal CA3 neurons in in vitro preparations are highest during the subjective night, when corticosterone levels are highest [123]. Similarly, Brunel and de Montigny [124] reported that the firing rate and pharmacological responsiveness of CA3 neurons is highest during the nocturnal peak in corticosterone secretion in vivo. Importantly, using hippocampal slice cultures, Chaudhury et al. demonstrated that the amplitude of LTP is greatest during the subjective night [125]. Additionally, Eckel-Mahan and colleagues reported circadian dependency in the efficiency of consolidation of long term memory [126].

Many studies support the idea that stress, a large part of whose actions are mediated by corticosteroids, influences learning and memory. Besides the quality and intensity of the stressor, the context in which the stressful stimulus is perceived, is an important determinant of the behavioral outcome. The latter is more easily explained in terms of 'intrinsic' and 'extrinsic stress [127]; 'intrinsic stress' refers to situations in which stress is either elicited by, or directly associated with, the cognitive experience (e.g. spatial learning), whereas 'extrinsic stress' describes situations in which the stress occurs outside the context of the momentary stress situation (e.g. foot shock stress before spatial learning). According to a model developed by Sandi and PineloNava [127], learning and memory will be facilitated by stressors that activate the same (or similar) neural circuitries that are required for interpreting and responding to a particular cognitive challenge. Supporting this view, Cahill and McGaugh [128] and Sandi [129] reported that emotionally arousing experiences are better remembered than neutral ones. In fear conditioning experiments, Cordero et al. noted that post-training corticosterone levels correlate with the strength of stimulus required to encode memories [130,131]. Moreover, the importance of corticosterone in information acquisition and consolidation of memory is well known, even if still poorly understood [132-135]. The relative importance of nMR and nGR in these processes are elegantly discussed by Schwabe et al. [136], and Revest et al. [134] have demonstrated a mediatory role of the MAPK pathway in the facilitation of hippocampus-dependent contextual fear conditioning by corticosteroids. In the previouslycited work on long-term contextual fear memory by Eckel-Mahan and colleagues [126], rhythms of MAPK (ERK1/2) activation were shown to coincide temporally with the degree of persistence of memory. Given that corticosterone acutely increases ERK1/2 phosphorylation $[51,116,117,134]$, the results presented by Eckel-Mahan and colleagues [126] should be considered in the context of the hypothesis proposed by Sandi and PineloNava [127] and the pioneering work by Oitzl and de Kloet [137]; in addition, since the amygdala plays a major part in the regulation of fear and has reciprocal interactions with the hippocampus and other cognitionregulating brain areas, future interpretations of the work by Eckel-Mahan and colleagues [126] should embrace the idea that corticosteroids can exert actions on a network of interconnected brain structures, whose individual responses will determine the ultimate behavioral output.

Besides the acute behavioral and physiological actions of corticosteroids, much research has been focused on understanding the influence of chronically elevated corticosteroid secretion. Notwithstanding the above-mentioned fact that corticosteroids may exert acute effects during the rising phase of the endocrine response to stress, it is important to note that the latter is, generally, a protracted one. Thus, while the acute rises in corticosteroid secretion may shape the overall long-term response, the longer duration of corticosteroid exposure after stress allows recruitment of an array of intracellular responses (including nuclear receptor-mediated events) and cellular, physiological and behavioral adaptations. It is important to note that, although the 
adrenocortical response to stress primarily serves an adaptive purpose, in certain circumstances, it may switch to being maladaptive, marked by transient or chronic pathology, as discussed earlier in this article.

The physiological and behavioral responses to stress depend on myriad molecules and processes, with an important contribution by corticosteroids; effects of the latter are often studied in isolation at the cost of other contributory factors and the neural networks which regulate, or may be regulated by, corticosteroids. This can be exemplified by considering our earlier discussion of corticosteroid interactions with glutamatergic transmission and reports that the direction and/or magnitude of LTP and LTD are influenced by the intensity and emotional value of a given stressor; for example, LTP is only reduced in animals exposed to uncontrollable stress [138], but not in animals that can escape from the stressor [139]. Using the paradigm of foot-shock stress, Wang et al. reported that stress induces a shift in synaptic plasticity; thus, whereas stress facilitates LTD induction, it impairs LTP induction [140]. Besides showing that these effects of stress can be blocked by RU 38486, these last authors showed that blockade of the NMDA receptor restores LTP inducibility in stressed animals; further they demonstrated that stress-induced changes in synaptic efficacy can be abolished by prior administration of Ro25-6981, a specific antagonist of the NR2B subunit of the NMDA receptor. A role for the NR2B subunit in the synaptic plasticity thought to be essential for the orchestration of the behavioral response to stress was also suggested by Wong et al. who showed that Ro25-6981 reverses elevated platform stress-induced deficits in spatial learning and memory, as tested in the Morris water maze (MWM) [141].

The NR2B subunit is predominantly associated with extrasynaptic NMDA receptors whose activation depends on glutamate "spill-over", a phenomenon that can be mimicked with threo- $\beta$-benzyloxyaspartate (TBOA), a blocker of glutamate re-uptake. Wong et al. [141] found that TBOA application to animals $5 \mathrm{~min}$ before low frequency stimulation resulted in the successful induction of LTD, indicating that stress leads to glutamate "spill-over". Linking LTD with stress-induced memory impairment, the authors showed that preventing LTD induction by infusion of a GluR2 peptide analogue that cannot be internalized abolished the ability of stress to cause memory deficits in the MWM test; these findings add to the evidence that acute stress results in the internalization of AMPA receptors, followed by synaptic depression and learning and memory deficits.

We previously discussed how the MAPK signaling pathways may be linked with LTP and LTD (and learning and memory). In this respect, it is interesting to note that this pathway is concomitantly activated by stress, presumably due to activation of nGR [142,143], believed to be essential for the phosphorylation of ERK1/2 [134]. Moreover, the observation that tail shock and restraint stress robustly activate ERK1/2 and impair synaptic potentiation in the CA1 subfield suggests a major role for the MAPK pathway in mediating the actions of stress [144]. In addition to inducing the phosphorylation of ERK1/2, stress activates other kinases (e. g. p38 MAPK, CaMKII) and pCREB within 2 min of swim stress [145]. Surprisingly, however, the latter responses are accompanied by a reinforcement (rather than impairment) of LTP in the dentate gyrus of the hippocampus. This finding indicates that different stressors may elicit quite different electrophysiological responses and/or, that the synaptic effects of stress differ from one hippocampal subfield to another. Since the effects of stress on biochemical and electrophysiological signalling in the dentate gyrus were found to be subject to modulation by serotonin [145], it is plausible that differential monoaminergic innervation of the different hippocampal subfields defines the ultimate cellular response.

We summarize some potential mechanisms that may account for the rapid and slower effects of corticosteroids on neuronal physiology, with a focus on synaptic events, in Figure 4. An attempt is made to show how signals originating at the neuronal surface are integrated both at the synaptic and transcriptional levels.

\section{Critique}

From the preceding, it appears safe to assume that, irrespective of the behavioural or physiological outcomes, acute and chronic elevations of corticosteroid secretion initiate common mechanisms and biochemical processes; convergence of these events will depend on parameters such as exposure dosage and time, as well as the context in which they occur. Given the potential for convergence (as well as potentiation), improved knowledge of the initial stages of corticosteroid signalling, whether membrane- or nuclear receptor-mediated, is clearly desirable. Studies on the rapid neural actions of corticosteroids are likely to gain further interest, especially as newer analytical tools become available and knowledge about the fast actions of other steroid hormones grows. It therefore seems appropriate to list some critical issues and needs, the consideration of which may foster progress through cautious reflection:

- definition of the terms "rapid" or "fast" actions of corticosteroids in terms of the timeframe within which a clearly defined (electro)physiological, biochemical and/or behavioural response is elicited in animals or neuronal cell and brain slice preparations; 


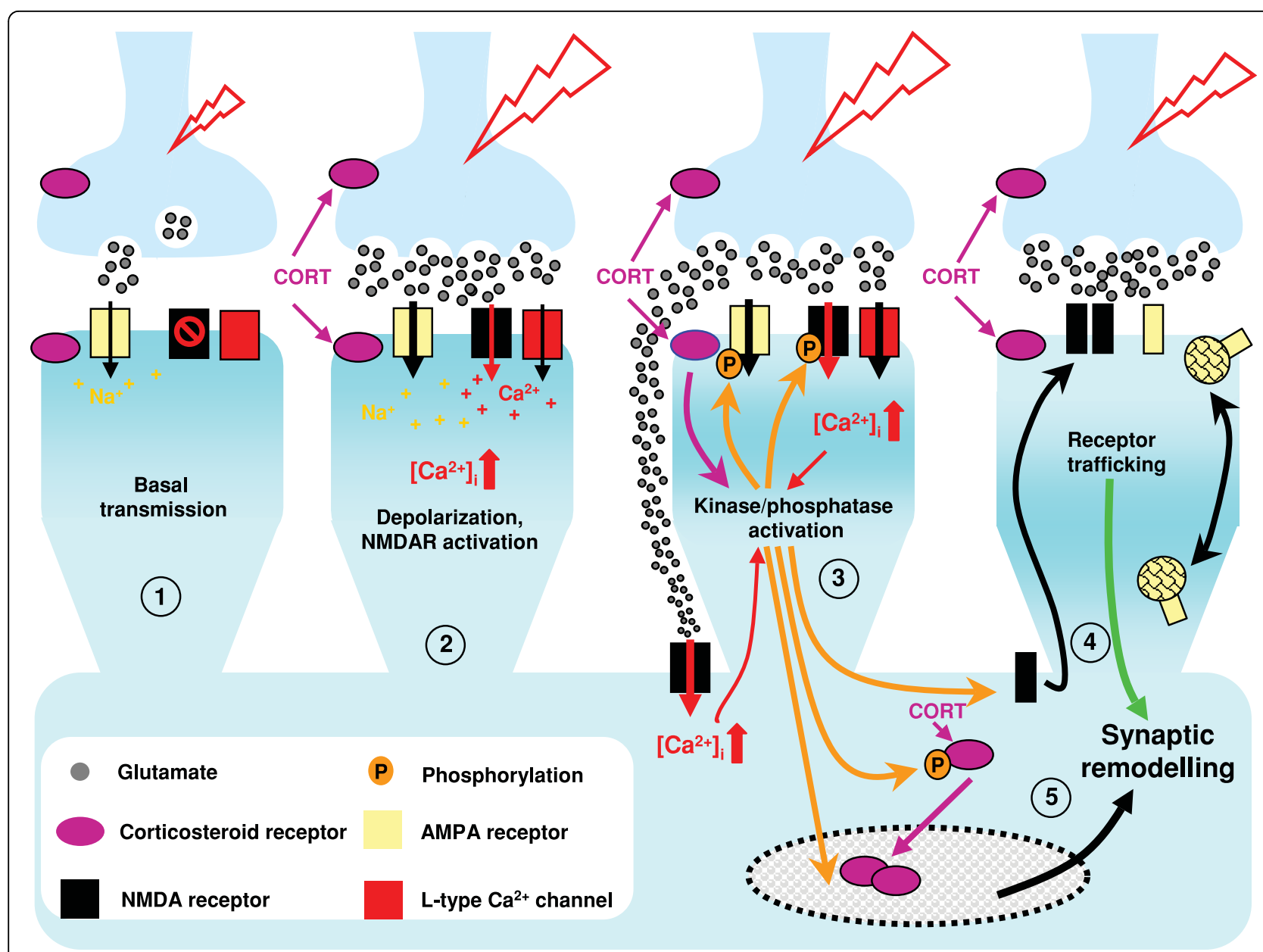

Figure 4 Working model of sequential corticosteroid influences on synaptic physiology. Corticosterone-mediated changes in synaptic transmission occur at different levels and in different sequential steps. (1) depicts synaptic transmission under basal conditions. Neuronal excitation results in glutamate secretion from synaptic vesicles at presynaptic sites into the synaptic cleft. Glutamate binds to postsynaptic glutamate-gated ion channels (in particular, AMPA receptors), which open to permit ion fluxes ( $\mathrm{Na}^{+}$influx, $\mathrm{K}^{+}$efflux) across the AMPA receptor, resulting in a depolarization of the postsynaptic cell. Due to a voltage-dependent $\mathrm{Mg}^{2+}$ block in its membrane domain, the NMDA receptor remains inactive under basal conditions, and is activated when a certain transmission threshold is reached. (2) Exposure to corticosteroids (e.g. during stress) may lead to activation of ERK1/2 in the presynaptic terminal (possibly through membrane corticosteroid receptors [51]); increased glutamatergic stimulation of postsynaptic AMPA receptors results in an increase in the frequency of AMPA receptor-mediated miniature postsynaptic currents (mEPSCs). (3) Enhanced activation of AMPA receptors in the previous step further depolarizes the postsynaptic membrane and activates NMDA receptors. Activated NMDA receptors ( $\mathrm{Na}^{+}$and $\mathrm{Ca}^{2+}$ influx, $\mathrm{K}^{+}$efflux) lead to further depolarization of the postsynaptic cell, resulting in the opening of voltage-dependent $\mathrm{Ca}^{2+}$ channels (VDCC) and high postsynaptic concentrations of $\mathrm{Ca}^{2+}$. Corticosteroids may stimulate glutamate secretion so strongly, causing glutamate "spill-over" which activates not only synaptic, but also extrasynaptic, glutamate receptors [141]; the latter are mainly NMDA receptors of the NR2B subtype. The increased intracellular levels of $\mathrm{Ca}^{2+}$ trigger a cascade of $\mathrm{Ca}^{2}$ ${ }^{+}$-dependent signaling pathways in the postsynaptic cell, which may, in turn, induce the phosphorylation and de-phosphorylation of postsynaptic glutamatergic receptors and of nuclear corticosteroid receptors (nMR and nGR). Activation of extrasynaptic NMDA receptors is thought to trigger NR2B-dependent kinases, which might initiate trafficking of extrasynaptic NR2B receptors into the postsynaptic surface. Furthermore, $\mathrm{Ca}^{2+}$-dependent signaling pathways in the postsynaptic cell participate in the regulation of AMPA receptor trafficking to and from the synaptic surface, as indicated in (4). Phosphorylation of nuclear corticosteroid receptors, influences their translocation to the nucleus and therefore, their transcriptional activity [32], as indicated in (5).

- standardized test protocols (steroid dose, animal or cellular models, and $\operatorname{sex}^{\mathrm{c}}$ of animals); in in vitro studies, drug diffusion times and active concentrations achieved at target cells should be controlled; similarly, in in vivo research, pharmacokinetic factors, including solvent and route of administration, should be considered; age of animals, but also of material used for in vitro testing, is important because of dynamic age-related changes in the expression of key partners such as glutamate receptor subunits [146]; since corticosteroids are secreted according to a strict circadian rhythm, both the 
availability of endogenous corticosteroids as well as of primary and secondary downstream effectors will vary over the day - this demands testing at a given circadian time to ensure comparable measurements [123-125].

- while surgical adrenalectomy is a useful approach to ensure that only the actions of exogenously-administered steroids are being recorded, the operation requires anaesthesia and may involve potentially confounding post-operative pain; chemical adrenalectomy is a good alternative (e.g. blockade of corticosteroid synthesis with metyrapone), but it may have (indirect) non-selective effects on the production of other steroids; adrenalectomy, in general, induces massive apoptosis and stimulates neurogenesis in the dentate gyrus within just a few hours, changes that probably result in reorganized neuronal circuits and measurable outputs [147].

- attention to the fact that acute and chronic corticosteroid exposures differ significantly, and that administration of corticosteroids only mimics an intermediate phase of the organism's response to stress;

- clear exclusion of transcriptional and translational events initiated by activation of cognate nuclear receptors;

\section{The show must (will) go on}

While the nuclear receptor-mediated actions of corticosteroids are well established, those that appear to be mediated through non-classical, possibly membranebound receptors, have perhaps not received sufficient appreciation. The lack of consistent results (see need for standardization in previous section), compounded by the relatively fruitless hunt for putative membrane receptors, accounts for the scepticism that haunts this area of research. Increased respectability might be gained by initially seeking answers to some of the following questions:

- How can the neural actions ascribed to peripherally-produced corticosteroids be distinguished from those that result from those elicited by corticosteroids thought to be produced in neural tissue?

- Can the rapid actions of corticosteroids observed predominantly in the CA1 subfield of the hippocampus be generalized to other hippocampal subfields, or indeed other brain regions?

- Do the endpoints assessed after application of corticosteroids reflect actions exclusively at the hippocampus? In vitro, do we get only a partial (or perhaps, false) picture? In vivo, are we monitoring responses from a network of corticosteroid-sensitive brain regions? How are the outputs modulated by other neurochemical states and inputs?

- Do corticosteroids directly interact with membrane proteins? What is the chemical identity of these molecules? Are they distinct from the known nuclear receptors and if not,

- Do they represent post-translational modifications (e.g. palmitoylated versions of the nuclear receptors, as suggested for the $\mathrm{mER}$ )?

- Is there biochemical evidence for interactions with other known membrane receptors (e.g. glutamate receptors); do these receptors have allosteric binding sites for corticosteroids as well as for pharmacological antagonists of nMR and nGR? (cf. estrogens, progestins)

- How do events that are triggered by corticosteroids at the membrane funnel into long-term cellular and organismic adaptations (e.g. by positive or negative priming of the gene machinery regulated by $\mathrm{nMR}$ and nGR)?

- How do the rapid actions of corticosteroids contribute to their longer-lasting actions (e.g. 'priming' of nuclear receptor-mediated events?)

- Is it possible to define corticosteroid actions - fast and slow - in terms of spatio-temporal maps, keeping in mind that damage induced in a relatively short time in one area may take longer to spread to other interconnected areas [cf. [13]]?

- Is it feasible to generate genetic or pharmacological tools that will facilitate acceptance and further study of $\mathrm{mCR}$ ?

\section{Appendix}

a) Corticosteroids: way upstream - the title of this article is adapted from Alan Ayckbourne's stage play Way Upstream in which two couples on a boating holiday run into some strange happenings.

b) A painted cloth in front of which a short scene is played while the main stage set is changed.

c) Research on the rapid actions of corticosteroids has mainly exploited male rodents or tissues derived from them. Corticosteroid secretion is strongly influenced by sex, as are physiology and behaviour. Many of the physiological and behavioural readouts monitored in such studies reflect the prevailing sex steroid milieu; in females, sex steroids are secreted in a cyclical fashion.

Additional file 1: Summary of rapid effects of corticosteroids and estrogens on the central nervous system [148-181]. Click here for file

[http://www.biomedcentral.com/content/supplementary/1756-6606-3-2S1.PDF ] 
Additional file 2: Synaptic plasticity and learning and memory [182221].

Click here for file

[http://www.biomedcentral.com/content/supplementary/1756-6606-3-2S2.PDF ]

\section{Acknowledgements}

The authors thank Silei Yang and members of the Munich and Bristol laboratories for their critique and encouragement. The article was written within the framework of the European Union's CRESCENDO Consortium (FP6 Contract LSHM-CT-2005-018652). TR was supported by LINE and a fellowship from the Max Planck Society.

\section{Author details}

'Max-Planck-Institute of Psychiatry, Kraepelin Str. 2-10, 80804 Munich, Germany. ${ }^{2}$ Henry Wellcome Laboratories for Integrative Neuroscience and Endocrinology, Faculty of Medicine and Dentistry, University of Bristol, Bristol, UK.

\section{Authors' contributions}

$\mathrm{TR}, \mathrm{AP}$ and OFX wrote the manuscript; KC critically reviewed the manuscript and suggested improvements. All authors read and approved the final form of the manuscript.

\section{Competing interests}

The authors declare that they have no competing interests.

\section{Received: 18 September 2009}

Accepted: 11 January 2010 Published: 11 January 2010

\section{References}

1. Chrousos GP, Gold PW: The concepts of stress and stress system disorders. Overview of physical and behavioral homeostasis. JAMA 1992, 267:1244-1252

2. Ye P, Kenyon CJ, Mackenzie SM, Nichol K, Seckl JR, Fraser R, Connell JM, Davies E: Effects of $\mathrm{ACTH}$, dexamethasone, and adrenalectomy on 11 beta-hydroxylase (CYP11B1) and aldosterone synthase (CYP11B2) gene expression in the rat central nervous system. J Endocrinol 2008, 196:305-311

3. Gomez-Sanchez EP, Ahmad N, Romero DG, Gomez-Sanchez CE: Is aldosterone synthesized within the rat brain?. Am J Physiol Endocrinol Metab 2005, 288:E342-346.

4. Lightman SL, Wiles CC, Atkinson HC, Henley DE, Russell GM, Leendertz JA, McKenna MA, Spiga F, Wood SA, Conway-Campbell BL: The significance of glucocorticoid pulsatility. Eur J Pharmacol 2008, 583:255-262.

5. Bassett JR, Cairncross KD: Time course for plasma 11-hydroxycorticosteroid elevation in rats during stress. Pharmacol Biochem Behav 1975, 3:139-142

6. Morilak DA, Barrera G, Echevarria DJ, Garcia AS, Hernandez A, Ma S, Petre CO: Role of brain norepinephrine in the behavioral response to stress. Prog Neuropsychopharmacol Biol Psychiatry 2005, 29:1214-1224.

7. Radley JJ, Williams B, Sawchenko PE: Noradrenergic innervation of the dorsal medial prefrontal cortex modulates hypothalamo-pituitaryadrenal responses to acute emotional stress. J Neurosci 2008, 28:5806-5816.

8. Yu S, Holsboer F, Almeida OF: Neuronal actions of glucocorticoids: focus on depression. J Steroid Biochem Mol Biol 2008, 108:300-309.

9. Fuchs $\mathrm{E}$, Gould $\mathrm{E}$ : Mini-review: in vivo neurogenesis in the adult brain: regulation and functional implications. Eur J Neurosci 2000, 12:2211-2214.

10. Starkman MN, Giordani B, Gebarski SS, Schteingart DE: Improvement in learning associated with increase in hippocampal formation volume. Biol Psychiatry 2003, 53:233-238.

11. Lupien SJ, McEwen BS, Gunnar MR, Heim C: Effects of stress throughout thelifespan on the brain, behaviour and cognition. Nat Rev Neurosci 2009, 10:434-445.

12. Gilpin H, Whitcomb D, Cho K: Atypical evening cortisol profile induces visual recognition memory deficit in healthy human subjects. Mol Brain 2008, 1:4.
13. Cerqueira JJ, Mailliet F, Almeida OF, Jay TM, Sousa N: The prefrontal cortex as a key target of the maladaptive response to stress. J Neurosci 2007, 27:2781-2787.

14. Holmes A, Wellman CL: Stress-induced prefrontal reorganization and executive dysfunction in rodents. Neurosci Biobehav Rev 2009, 33:773-783.

15. Radley JJ, Rocher AB, Rodriguez A, Ehlenberger DB, Dammann M, McEwen BS, Morrison JH, Wearne SL, Hof PR: Repeated stress alters dendritic spine morphology in the rat medial prefrontal cortex. J Comp Neurol 2008, 507:1141-1150

16. Sousa N, Almeida OFX: Corticosteroids: sculptors of the hippocampal formation. Rev Neurosci 2002, 13:59-84.

17. Grillo CA, Piroli GG, Wood GE, Reznikov LR, McEwen BS, Reagan LP: Immunocytochemical analysis of synaptic proteins provides new insights into diabetes-mediated plasticity in the rat hippocampus. Neuroscience 2005, 136:477-486

18. Bessa JM, Ferreira D, Melo I, Marques F, Cerqueira JJ, Palha JA, Almeida OFX Sousa N: Hippocampal neurogenesis induced by antidepressant drugs: an epiphenomenon in their mood-improving actions. Mol Psychiatry 2009, 14:739.

19. Sotiropoulos I, Catania C, Riedemann T, Fry JP, Breen KC, Michaelidis TM Almeida OFX: Glucocorticoids trigger Alzheimer disease-like pathobiochemistry in rat neuronal cells expressing human tau. J Neurochem 2008, 107:385-397.

20. de Kloet ER, Joëls M, Holsboer F: Stress and the brain: from adaptation to disease. Nat Rev Neurosci 2005, 6:463-475.

21. Reul JM, de Kloet ER: Anatomical resolution of two types of corticosterone receptor sites in rat brain with in vitro autoradiography and computer-ized image analysis. J Steroid Biochem 1986, 24:269-272.

22. Reul JM, Gesing A, Droste S, Stec IS, Weber A, Bachmann C, Bilang-Bleuel A, Holsboer F, Linthorst AC: The brain mineralocorticoid receptor: greedy for ligand, mysterious in function. Eur J Pharmacol 2000, 405:235-249.

23. Seckl JR, Holmes MC: Mechanisms of disease: glucocorticoids, their placental metabolism and fetal 'programming' of adult pathophysiology. Nat Clin Pract Endocrinol Metab 2007, 3:479-488.

24. Gronemeyer H, Gustafsson JA, Laudet V: Principles for modulation of the nuclear receptor superfamily. Nat Rev Drug Discov 2004, 3:950-964.

25. Rosenhagen MC, Sōti C, Schmidt U, Wochnik GM, Hartl FU, Holsboer F, Young JC, Rein T: The heat shock protein 90-targeting drug cisplatin selectively inhibits steroid receptor activation. Mol Endocrinol 2003, 17:1991-2001.

26. Edlich F, Weiwad M, Wildemann D, Jarczowski F, Kilka S, Moutty MC Jahreis G, Lücke C, Schmidt W, Striggow F, Fischer G: The specific FKBP38 inhibitor $\mathrm{N}$-( $\mathrm{N}^{\prime}, \mathrm{N}^{\prime}$ dimethylcarboxamidomethyl) cycloheximide has potent neuroprotective and neurotrophic properties in brain ischemia. J Biol Chem 2006, 281:14961-14970.

27. Tata JR: Hormonal regulation of growth and protein synthesis. Nature 1968, 219:331-337.

28. Kawakami M, Sawyer CH: Neuroendocrine correlates of changes in brain activity thresholds by sex steroids and pituitary hormones. Endocrinology 1959, 65:652-668.

29. Woolley DE, Timiras PS: The gonad-brain relationship: effects of female sex hormones on electroshock convulsions in the rat. Endocrinology 1962, 70:196-209.

30. Chen D, Washbrook E, Sarwar N, Bates GJ, Pace PE, Thirunuvakkarasu V, Taylor J, Epstein RJ, Fuller-Pace FV, Egly JM, Coombes RC, Ali S: Phosphorylation of human estrogen receptor alpha at serine 118 by two distinct signal transduction pathways revealed by phosphorylationspecific antisera. Oncogene 2002, 21:4921-4931.

31. Bruck N, Vitoux D, Ferry C, Duong V, Bauer A, de Thé H, Rochette-Egly C: A coordinated phosphorylation cascade initiated by p38MAPK/MSK1 directs RARalpha to target promoters. EMBO J 2009, 28:34-47.

32. Kino T, Ichijo T, Amin ND, Kesavapany S, Wang Y, Kim N, Rao S, Player A, Zheng YL, Garabedian MJ, Kawasaki E, Pant HC, Chrousos GP: Cyclindependent kinase 5 differentially regulates the transcriptional activity of the glucocorticoid receptor through phosphorylation: clinical implications for the nervous system response to glucocorticoids and stress. Mol Endocrinol 2007, 21:1552-1568.

33. Bliss TV, Lomo T: Long-lasting potentiation of synaptic transmission in the dentate area of the anaesthetized rabbit following stimulation of the perforant path. J Physiol 1973, 232:331-356. 
34. Bliss TV, Collingridge GL: A synaptic model of memory: long-term potentiation in the hippocampus. Nature 1993, 361:31-39.

35. Stanton PK, Sejnowski TJ: Associative long-term depression in the hippocampus induced by hebbian covariance. Nature 1989, 339:215-218.

36. Wilson $M$, Critchlow V: Effect of fornix transection or hippocampectomy on rhythmic pituitary-adrenal function in the rat. Neuroendocrinology 1974, 13:1973-29.

37. Sapolsky RM, Plotsky PM: Hypercortisolism and its possible neural bases. Biol Psychiatry 1990, 27:937-952.

38. Wintermantel TM, Berger S, Greiner EF, Schütz G: Evaluation of steroid receptor function by gene targeting in mice. J Steroid Biochem Mol Biol 2005, 93:107-112.

39. Mizoguchi K, Ishige A, Takeda S, Aburada M, Tabira T: Endogenous glucocorticoids are essential for maintaining prefrontal cortical cognitive function. J Neurosci 2004, 24:5492-5499.

40. Ulrich-Lai YM, Herman JP: Neural regulation of endocrine and autonomic stress responses. Nat Rev Neurosci 2009, 10:397-409.

41. Radley JJ, Gosselink KL, Sawchenko PE: A discrete GABAergic relay mediates medial prefrontal cortical inhibition of the neuroendocrine stress response. J Neurosci 2009, 29:7330-7340.

42. Dias-Ferreira E, Sousa JC, Melo I, Morgado P, Mesquita AR, Cerqueira JJ, Costa RM, Sousa N: Chronic stress causes frontostriatal reorganization and affects decision-making. Science 2009, 325:621-625.

43. Jaferi A, Bhatnagar S: Corticosterone can act at the posterior paraventricular thalamus to inhibit hypothalamic-pituitary-adrenal activity in animals that habituate to repeated stress. Endocrinology 2006, 147:4917-4930.

44. Roozendaal B, McEwen BS, Chattarji S: Stress, memory and the amygdala. Nat Rev Neurosci 2009, 10:423-433.

45. Piazza PV, Le Moal ML: Pathophysiological basis of vulnerability to drug abuse: role of an interaction between stress, glucocorticoids, and dopaminergic neurons. Annu Rev Pharmacol Toxicol 1996, 36:359-378.

46. Katz DB, Steinmetz JE: Psychological functions of the cerebellum. Behav Cogn Neurosci Rev 2002, 1:229-241.

47. Roozendaal B, Quirarte GL, McGaugh JL: Glucocorticoids interact with the basolateral amygdala beta-adrenoceptor-cAMP/cAMP/PKA system in influencing memory consolidation. Eur J Neurosci 2002, 15:553-560.

48. Campolongo P, Roozendaal B, Trezza V, Hauer D, Schelling G, McGaugh JL, Cuomo V: Endocannabinoids in the rat basolateral amygdala enhance memory consolidation and enable glucocorticoid modulation of memory. Proc Natl Acad Sci USA 2009, 106:4888-4893.

49. Cho K, Little HJ: Effects of corticosterone on excitatory amino acid responses in dopamine-sensitive neurons in the ventral tegmental area. Neuroscience 1999, 88:837-845.

50. Karst H, Berger S, Turiault M, Tronche F, Schütz G, Joëls M: Mineralocorticoid receptors are indispensable for nongenomic modulation of hippocampal glutamate transmission by corticosterone. Proc Natl Acad Sci USA 2005, 102:19204-19207.

51. Olijslagers JE, de Kloet ER, Elgersma Y, van Woerden GM, Joëls M, Karst H: Rapid changes in hippocampal CA1 pyramidal cell function via pre- as well as postsynaptic membrane mineralocorticoid receptors. Eur J Neurosci 2008, 27:2542-2550.

52. Hart SA, Snyder MA, Smejkalova T, Woolley CS: Estrogen mobilizes a subset of estrogen receptor-alpha-immunoreactive vesicles in inhibitory presynaptic boutons in hippocampal CA1. J Neurosci 2007, 27:2102-2111.

53. Kalita K, Szymczak S, Kaczmarek L: Non-nuclear estrogen receptor beta and alpha in the hippocampus of male and female rats. Hippocampus 2005, 15:404-412.

54. Milner TA, Ayoola K, Drake CT, Herrick SP, Tabori NE, McEwen BS, Warrier S, Alves SE: Ultrastructural localization of estrogen receptor beta immunoreactivity in the rat hippocampal formation. J Comp Neurol 2005, 491:81-95.

55. Qiu J, Bosch MA, Tobias SC, Krust A, Graham SM, Murphy SJ, Korach KS, Chambon P, Scanlan TS, Rønnekleiv OK, Kelly MJ: A G-protein-coupled estrogen receptor is involved in hypothalamic control of energy homeostasis. J Neurosci 2006, 26:5649-5655.

56. Qiu J, Bosch MA, Tobias SC, Grandy DK, Scanlan TS, Ronnekleiv OK, Kelly MJ: Rapid signaling of estrogen in hypothalamic neurons involves a novel G-protein-coupled estrogen receptor that activates protein kinase C. J Neurosci 2003, 23:9529-9540.
57. Revankar CM, Cimino DF, Sklar LA, Arterburn JB, Prossnitz ER: A transmembrane intracellular estrogen receptor mediates rapid cell signaling. Science 2005, 307:1625-1630.

58. Thomas P, Pang Y, Filardo EJ, Dong J: Identity of an estrogen membrane receptor coupled to a $\mathrm{G}$ protein in human breast cancer cells. Endocrinology 2005, 146:624-632.

59. Filardo EJ, Quinn JA, Frackelton AR Jr, Bland Kl: Estrogen action via the $G$ protein-coupled receptor, GPR30: stimulation of adenylyl cyclase and cAMP-mediated attenuation of the epidermal growth factor receptor-toMAPK signaling axis. Mol Endocrinol 2002, 16:70-84.

60. Qiu J, Rønnekleiv OK, Kelly MJ: Modulation of hypothalamic neuronal activity through a novel G-protein-coupled estrogen membrane receptor. Steroids 2008, 73:985-991.

61. Revankar CM, Mitchell HD, Field AS, Burai R, Corona C, Ramesh C, Sklar LA, Arterburn JB, Prossnitz ER: Synthetic estrogen derivatives demo-nstrate the functionality of intracellular GPR30. ACS Chem Biol 2007, 2:536-544.

62. Toran-Allerand CD, Guan X, MacLusky NJ, Horvath TL, Diano S, Singh M, Connolly ES Jr, Nethrapalli IS, Tinnikov AA: ER-X: a novel, plasma membrane-associated, putative estrogen receptor that is regulated during development and after ischemic brain injury. J Neurosci 2002, 22:8391-8401.

63. Singh M, Sétáló G Jr, Guan X, Frail DE, Toran-Allerand CD: Estrogeninduced activation of the mitogen-activated protein kinase cascade in the cerebral cortex of estrogen receptor-alpha knock-out mice. J Neurosci 2000, 20:1694-1700.

64. Willmer EN: Steroids and cell surfaces. Biol Rev Camb Philos Soc 1961, 36:368-398.

65. Jensen EV: From chemical warfare to breast cancer management. Nat Med 2004, 10:1018-1021.

66. Tata JR: Signalling through nuclear receptors. Nat Rev Mol Cell Biol 2002, 3:702-710.

67. Satre $M$, Vignais PV: Steroid 11 beta-hydroxylation in beef adrenal cortex mitochondria. Binding affinity and capacity of specific (14C)steroids and for $(3 \mathrm{H})$ metyrapol, an inhibitor of the 11 beta-hydroxylation reaction. Biochemistry 1974, 13:2201-2209.

68. Gametchu B: Glucocorticoid receptor-like antigen in lymphoma cell membranes: correlation to cell lysis. Science 1987, 236:456-461.

69. Orchinik M, Murray TF, Moore FL: A corticosteroid receptor in neuronal membranes. Science 1991, 252:1848-1851.

70. Ke FC, Ramirez VD: Binding of progesterone to nerve cell membranes of rat brain using progesterone conjugated to 1251-bovine serum albumin as a ligand. J Neurochem 1990, 54:467-472.

71. Kelly MJ, Moss RL, Dudley CA: The effect of ovariectomy on the responsiveness of preoptic-septal neurons to microelectrophoresed estrogen Neuroendocrinology 1978, 25:204-211.

72. Towle AC, Sze PY: Steroid binding to synaptic plasma membrane: differential binding of glucocorticoids and gonadal steroids. J Steroid Biochem 1983, 18:135-143.

73. Orchinik M, Hastings N, Witt D, McEwen BS: High-affinity binding of corticosterone to mammalian neuronal membranes: possible role of corticosteroid binding globulin. J Steroid Biochem Mol Biol 1997, 60:229-236.

74. Breuner CW, Orchinik M: Pharmacological characterization of intracellular, membrane, and plasma binding sites for corticosterone in house sparrows. Gen Comp Endocrinol 2009, 163:214-224.

75. Orchinik M, Murray TF, Franklin PH, Moore FL: Guanyl nucleotides modulate binding to steroid receptors in neuronal membranes. Proc Natl Acad Sci USA 1992, 89:3830-3834.

76. Evans SJ, Murray TF, Moore FL: Partial purification and biochemical characterization of a membrane glucocorticoid receptor from an amphibian brain. J Steroid Biochem Mol Biol 2000, 72:209-221.

77. Johnson LR, Farb C, Morrison JH, McEwen BS, LeDoux JE: Localization of glucocorticoid receptors at postsynaptic membranes in the lateral amygdala. Neuroscience 2005, 136:189-299.

78. Liposits Z, Bohn MC: Association of glucocorticoid receptor immunoreactivity with cell membrane and transport vesicles in hippocampal and hypothalamic neurons of the rat. J Neurosci Res 1993, 35:14-19.

79. Razandi M, Alton G, Pedram A, Ghonshani S, Webb P, Levin ER: Identification of a structural determinant necessary for the localization and function of estrogen receptor alpha at the plasma membrane. Mol Cell Biol 2003, 23:1633-1646. 
80. Pedram A, Razandi M, Sainson RC, Kim JK, Hughes CC, Levin ER: A conserved mechanism for steroid receptor translocation to the plasma membrane. J Biol Chem 2007, 282:22278-22288.

81. Matthews L, Berry A, Ohanian V, Ohanian J, Garside H, Ray D: Caveolin mediates rapid glucocorticoid effects and couples glucocorticoid action to the atiproliferative program. Mol Endocrinol 2008, 22:1320-1330.

82. Pratt WB: The role of the hsp90-based chaperone system in signal transduction by nuclear receptors and receptors signaling via MAP kinase. Annu Rev Pharmacol Toxicol 1997, 37:297-326.

83. Sétáló G Jr, Singh M, Guan X, Toran-Allerand CD: Estradiol-induced phosphorylation of ERK1/2 in explants of the mouse cerebral cortex: the roles of heat shock protein 90 (Hsp90) and MEK2. J Neurobiol 2002, 50:1-12.

84. Widén C, Zilliacus J, Gustafsson JA, Wikström AC: Glucocorticoid receptor interaction with 14-3-3 and Raf-1, a proposed mechanism for cross-talk of two signal transduction pathways. J Biol Chem 2000, 275:39296-39301.

85. Bouzat C, Barrantes FJ: Modulation of muscle nicotinic acetylcholine receptors by the glucocorticoid hydrocortisone. Possible allosteric mechanism of channel blockade. J Biol Chem 1996, 271:25835-25841.

86. Sedlácek M, Korínek M, Petrovic M, Cais O, Adamusová E, Chodounská H, Vyklický $L$ Jr: Neurosteroid modulation of ionotropic glutamate receptors and excitatory synaptic transmission. Physiol Res 2008, 57:S49-57.

87. Hosie AM, Wilkins ME, Smart TG: Neurosteroid binding sites on GABA(A) receptors. Pharmacol Ther 2007, 116:7-19.

88. Kasai M, Kannan H, Ueta $Y$, Osaka T, Inenaga K, Yamashita H: Effects of iontophoretically applied cortisol on tuberoinfundibular neurons in hypo-thalamic paraventricular nucleus of anesthetized rats. Neurosci Lett 1988, 87:35-40.

89. Kasai $\mathrm{M}$, Yamashita $\mathrm{H}$ : Inhibition by cortisol of neurons in the paraventricular nucleus of the hypothalamus in adrenalectomized rats; an in vitro study. Neurosci Lett 1988, 91:59-64.

90. Kasai M, Yamashita H: Cortisol suppresses noradrenaline-induced excitatory responses of neurons in the paraventricular nucleus; an in vitro study. Neurosci Lett 1988, 91:65-70.

91. Saphier D, Feldman S: Iontophoretic application of glucocorticoids inhibits identified neurones in the rat paraventricular nucleus. Brain Res 1988, 453:183-190

92. Mor G, Saphier D, Feldman S: Inhibition by corticosterone of paraventricular nucleus multiple-unit activity responses to sensory stimuli in freely moving rats. Exp Neurol 1986, 94:391-399.

93. Sato S, Osanai H, Monma T, Harada T, Hirano A, Saito M, Kawato S: Acute effect of corticosterone on N-methyl-D-aspartate receptor-mediated Ca2 + elevation in mouse hippocampal slices. Biochem Biophys Res Commun 2004, 321:510-513

94. Barak YB, Gutnick MJ, Feldman S: Iontophoretically applied corticosteroids do not affect the firing of hippocampal neurons. Neuroendocrinology 1977, 23:248-256.

95. Vidal C, Jordan W, Zieglgänsberger W: Corticosterone reduces the excitability of hippocampal pyramidal cells in vitro. Brain Res 1986, 383:54-59.

96. Joëls $M$, de Kloet ER: Mineralocorticoid receptor-mediated changes in membrane properties of rat CA1 pyramidal neurons in vitro. Proc Natl Acad Sci USA 1990, 87:4495-4498.

97. Beck SG, List TJ, Choi KC: Long- and short-term administration of corticosterone alters CA1 hippocampal neuronal properties. Neuroendocrinology 1994, 60:261-272.

98. Rey M, Carlier E, Soumireu-Mourat B: Effects of corticosterone on hippocampal slice electrophysiology in normal and adrenalectomized BALB/C mice. Neuroendocrinology 1987, 46:424-429.

99. Shah MM, Haylett DG: K+ currents generated by NMDA receptor activateion in rat hippocampal pyramidal neurons. J Neurophysiol 2002, 87:2983-2989.

100. Hotson JR, Prince DA: A calcium-activated hyperpolarization follows repetitive firing in hippocampal neurons. J Neurophysiol 1980, 43:409-419.

101. Kerr DS, Campbell LW, Thibault O, Landfield PW: Hippocampal glucocorticoid receptor activation enhances voltage-dependent $\mathrm{Ca} 2+$ conduct-ances: relevance to brain aging. Proc Natl Acad Sci USA 1992, 89:8527-8531.

102. Tian L, Knaus HG, Shipston MJ: Glucocorticoid regulation of calciumactivated potassium channels mediated by serine/threonine protein phosphatase. J Biol Chem 1998, 273:13531-13536.
103. Shipston MJ, Kelly JS, Antoni FA: Glucocorticoids block protein kinase A inhibition of calcium-activated potassium channels. J Biol Chem 1996, 271:9197-9200.

104. Wiegert O, Pu Z, Shor S, Joëls M, Krugers H: Glucocorticoid receptor activation selectively hampers $\mathrm{N}$-methyl-D-aspartate receptor dependent hippocampal synaptic plasticity in vitro. Neuroscience 2005, 135:403-411.

105. Chameau P, Qin Y, Spijker S, Smit G, Joëls M: Glucocorticoids specific-ally enhance L-type calcium current amplitude and affect calcium chan-nel subunit expression in the mouse hippocampus. J Neurophysiol 2007, 97:5-14.

106. Karst H, Karten YJ, Reichardt HM, de Kloet ER, Schütz G, Joëls M: Corticosteroid actions in hippocampus require DNA binding of glucocorticoid receptor homodimers. Nat Neurosci 2000, 3:977-978.

107. Krugers HJ, Alfarez DN, Karst H, Parashkouhi K, van Gemert N, Joëls M: Corticosterone shifts different forms of synaptic potentiation in opposite directions. Hippocampus 2005, 15:697-703.

108. Martin S, Henley JM, Holman D, Zhou M, Wiegert O, van Spronsen M, Joëls M, Hoogenraad CC, Krugers HJ: Corticosterone alters AMPAR mobility and facilitates bidirectional synaptic plasticity. PLOS One 2009, 4: e4714.

109. Karst H, Joëls M: Corticosterone slowly enhances miniature excitatory ostsynaptic current amplitude in mice CA1 hippocampal cells. J Neurophysiol 2005, 94:3479-3486.

110. Liu L, Wang C, Ni X, Sun J: A rapid inhibition of NMDA receptor current by corticosterone in cultured hippocampal neurons. Neurosci Lett 2007, 420:245-250.

111. Takahashi T, Kimoto T, Tanabe N, Hattori TA, Yasumatsu N, Kawato S: Corticosterone acutely prolonged $\mathrm{N}$-methyl-d-aspartate receptormediated $\mathrm{Ca}^{2+}$ elevation in cultured rat hippocampal neurons. $J$ Neurochem 2002, 83:1441-1451

112. ffrench-Mullen JM: Cortisol inhibition of calcium currents in guinea pig hippocampal CA1 neurons via G-protein-coupled activation of protein kinase C. J Neurosci 1995, 15:903-911.

113. Sze PY, Iqbal Z: Glucocorticoid action on depolarization-dependent calcium influx in brain synaptosomes. Neuroendocrinology 1994, 59:457-465.

114. Wiegert $\mathrm{O}$, Joëls $M$, Krugers $H$ : Timing is essential for rapid effects of corticosterone on synaptic potentiation in the mouse hippocampus. Learn Mem 2006, 13:110-113.

115. Groc L, Choquet D, Chaouloff F: The stress hormone corticosterone conditions AMPAR surface trafficking and synaptic potentiation. Nat Neurosci 2008, 11:868-870.

116. Chen YZ, Qiu J: Possible genomic consequence of nongenomic action of glucocorticoids in neural cells. News in Physiological Sciences 2001, 16:292-296.

117. Qi AQ, Qiu J, Xiao L, Chen YZ: Rapid activation of JNK and p38 by glucocorticoids in primary cultured hippocampal cells. J Neurosci Res 2005, 80:510-517.

118. Dallman MF: Fast glucocorticoid actions on brain: back to the future. Front Neuroendocrinol 2005, 26:103-108.

119. Mikics E, Kruk MR, Haller J: Genomic and non-genomic effects of glucocorticoids on aggressive behavior in male rats. Psychoneuroendocrinology 2004, 29:618-635.

120. Mikics E, Barsy B, Haller J: The effect glucocorticoids on aggressiveness in established colonies of rats. Psychoneuroendocrinology 2007, 32:160-170.

121. Mikics E, Barsy B, Barsvári B, Haller J: Behavioral specificity of non-genomic glucocorticoid effects in rats: effects on risk assessment in the elevated plus-maze and the open-field. Horm Behav 2005, 48:152-162.

122. Sandi C, Venero C, Guaza C: Novelty-related rapid locomotor effects of corticosterone in rats. Eur J Neurosci 1996, 8:794-800.

123. Kole MH, Koolhaas JM, Luiten PG, Fuchs E: High-voltage-activated Ca2+ currents and the excitability of pyramidal neurons in the hippocampal CA3 subfield in rats depend on corticosterone and time of day. Neurosci Lett 2001, 307:53-56.

124. Brunel S, de Montigny C: Diurnal rhythms in the responsiveness of hippocampal pyramidal neurons to serotonin, norepinephrine, gammaaminobutyric acid and acetylcholine. Brain Res Bull 1987, 18:205-212.

125. Chaudhury D, Wang LM, Colwell CS: Circadian regulation of hippo-campal long-term potentiation. J Biol Rhythms 2005, 20:225-236 
126. Eckel-Mahan KL, Phan T, Han S, Wang H, Chan GC, Scheiner ZS, Storm DR Circadian oscillation of hippocampal MAPK activity and cAMP: implications for memory persistence. Nat Neurosci 2008, 11:1074-1082.

127. Sandi C, Pinelo-Nava MT: Stress and memory: behavioral effects and neurobiological mechanisms. Neural Plast 2007, 2007:78970.

128. Cahill L, McGaugh JL: Mechanisms of emotional arousal and lasting declarative memory. Trends Neurosci 1998, 21:294-299.

129. Sandi C: The role and mechanisms of action of glucocorticoid involvement in memory storage. Neural Plast 1998, 6:41-52.

130. Cordero MI, Merino JJ, Sandi C: Correlational relationship between shock intensity and corticosterone secretion on the establishment and subsequent expression of contextual fear conditioning. Behav Neurosci 1998, 112:885-891.

131. Cordero Ml, Kruyt ND, Merino JJ, Sandi C: Glucocorticoid involvement in memory formation in a rat model for traumatic memory. Stress 2002, 5:73-79.

132. Cordero Ml, Sandi C: A role for brain glucocorticoid receptors in contextual fear conditioning: dependence upon training intensity. Brain Res 1998, 786:11-17.

133. Roozendaal B, McGaugh JL: Glucocorticoid receptor agonist and antagonist administration into the basolateral but not central amygdala modulates memory storage. Neurobiol Learn Mem 1997, 67:176-179.

134. Revest JM, Di Blasi F, Kitchener P, Rougé-Pont F, Desmedt A, Turiault M, Tronche F, Piazza PV: The MAPK pathway and Egr-1 mediate stressrelated behavioral effects of glucocorticoids. Nat Neurosci 2005, 8:664-672.

135. de Kloet ER, Oitzl MS, Joëls M: Stress and cognition: are corticosteroids good or bad guys?. Trends Neurosci 1999, 22:422-426.

136. Schwabe L, Schächinger H, de Kloet ER, Oitzl MS: Corticosteroids operate as switch between memory systems. J Cogn Neurosci 2009.

137. Oitzl MS, de Kloet ER: Selective corticosteroid antagonists modulate specific aspects of spatial orientation learning. Behav Neurosci 1992, 106:62-71.

138. Foy MR, Stanton ME, Levine S, Thompson RF: Behavioral stress impairs long-term potentiation in rodent hippocampus. Behav Neural Biol 1987, 48:138-149.

139. Shors TJ, Seib TB, Levine S, Thompson RF: Inescapable versus escapable shock modulates long-term potentiation in the rat hippocampus. Science 1989, 244:224-226.

140. Wang M, Yang Y, Dong Z, Cao J, Xu L: NR2B-containing N-methyl-Daspartate subtype glutamate receptors regulate the acute stress effect on hippocampal long-term potentiation/long-term depression in vivo. Neuroreport 2006, 17:1343-1346.

141. Wong TP, Howland JG, Robillard JM, Ge Y, Yu W, Titterness AK, Brebner K, Liu L, Weinberg J, Christie BR, Phillips AG, Wang YT: Hippocampal longterm depression mediates acute stress-induced spatial memory retrieval impairment. Proc Natl Acad Sci USA 2007, 104:11471-11476.

142. Meller E, Shen C, Nikolao TA, Jensen C, Tsimberg Y, Chen J, Gruen RJ: Region-specific effects of acute and repeated restraint stress on the phosphorylation of mitogen-activated protein kinases. Brain Res 2003, 979:57-64.

143. Sananbenesi F, Fischer A, Schrick C, Spiess J, Radulovic J: Mitogen-activated protein kinase signaling in the hippocampus and its modulation by corticotropin releasing factor receptor 2: a possible link between stress and fear memory. J Neurosci 2003, 23:11436-11443.

144. Yang CH, Huang CC, Hsu KS: Behavioral stress modifies hippocampal synaptic plasticity through corticosterone-induced sustained extracellular signal-regulated kinase/mitogen-activated protein kinase activation. J Neurosci 2004, 24:11029-11034.

145. Ahmed T, Frey JU, Korz V: Long-term effects of brief acute stress on cellular signaling and hippocampal LTP. J Neurosci 2006, 26:3951-3958,

146. Monyer H, Burnashev N, Laurie DJ, Sakmann B, Seeburg PH: Developmental and regional expression in the rat brain and functional properties of four NMDA receptors. Neuron 1994, 12:529-540.

147. Crick C, Miranker W: Apoptosis, neurogenesis, and information content in Hebbian networks. Biol Cybern 2006, 94:9-19.

148. Sandi C, Venero C, Guaza C: Nitric oxide synthesis inhibitors prevent rapid behavioral effects of corticosterone in rats. Neuroendocrinology 1996, 63:446-453.

149. Kruk MR, Halász J, Meelis W, Haller J: Fast positive feedback between the adrenocortical stress response and a brain mechanism involved in aggressive behavior. Behav Neurosci 2004, 118:1062-1070.
150. de Quervain DJ, Roozendaal B, Nitsch RM, McGaugh JL, Hock C: Acute cortisone administration impairs retrieval of long-term declarative memory in humans. Nat Neurosci 2000, 3:313-314.

151. de Quervain DJ, Roozendaal B, McGaugh JL: Stress and glucocorticoids impair retrieval of long-term spatial memory. Nature 1998, 394:787-790.

152. Sajadi AA, Samaei SA, Rashidy-Pour A: Intra-hippocampal micro-injections of anisomycin did not block glucocorticoid-induced impairment of memory retrieval in rats: an evidence for non-genomic effects of glucocorticoids. Behav Brain Res 2006, 173:158-162.

153. Roozendaal B, de Quervain DJ, Schelling G, McGaugh JL: A systemically administered beta-adrenoceptor antagonist blocks corticosteroneinduced impairment of contextual memory retrieval in rats. Neurobiol Learn Mem 2004, 81:150-154.

154. Kent WD, Cross-Mellor SK, Kavaliers M, Ossenkopp KP: Acute effects of corticosterone on LiCl-induced rapid gustatory conditioning in rats: a taste reactivity analysis. Neuroreport 2000, 11:3903-3908.

155. Kent WD, Cross-Mellor SK, Kavaliers M, Ossenkopp KP: Acute effects of corticosterone on LiCl-induced rapid gustatory conditioning in rats: a microstructural analysis of licking patterns. Behav Brain Res 2002, 136:143-150.

156. Piazza PV, Rougé-Pont F, Deroche V, Maccari S, Simon H, Le Moal M: Glucocorticoids have state-dependent stimulant effects on the mesenceph-alic dopaminergic transmission. Proc Natl Acad Sci USA 1996, 93:8716-8720.

157. Avanzino GL, Ermirio R, Cogo CE, Ruggeri P, Molinari C: Effects of corticosterone on neurones of the locus coeruleus, in the rat. Neurosci Lett 1987, 80:85-88.

158. Gründemann D, Schechinger B, Rappold GA, Schömig E: Molecular identification of the corticosterone-sensitive extraneuronal catecholamine transporter. Nat Neurosci 1998, 1:349-351.

159. Qiu J, Wang P, Jing Q, Zhang W, Li X, Zhong Y, Sun G, Pei G, Chen Y: Rapid activation of ERK1/2 mitogen-activated protein kinase by cortico-sterone in PC12 cells. Biochem Biophys Res Commun 2001, 287:1017-1024.

160. Li X, Qiu J, Wang J, Zhong Y, Zhu J, Chen Y: Corticosterone-induced rapid phosphorylation of p38 and JNK mitogen-activated protein kinases in PC12 cells. FEBS Lett 2001, 492:210-214.

161. Dallman MF, Yates FE: Dynamic asymmetries in the corticosteroid feedback path and distribution-metabolism-binding elements of the adrenocortical system. Ann NY Acad Sci 1969, 156:696-721.

162. Chen YZ, Hua SY, Wang CA, Wu LG, Gu Q, Xing BR: An electrophysiological study on the membrane receptor-mediated action of glucocorticoids in mammalian neurons. Neuroendocrinology 1991, 53:25-30.

163. Di S, Malcher-Lopes R, Halmos KC, Tasker JG: Nongenomic glucocort-icoid inhibition via endocannabinoid release in the hypothalamus: a fast feedback mechanism. J Neurosci 2003, 23:4850-4857.

164. Tasker JG, Di S, Malcher-Lopes R: Minireview: rapid glucocorticoid signaling via membrane-associated receptors. Endocrinology 2006, 147:5549-5556.

165. Kelly MJ, Rønnekleiv OK: Control of CNS neuronal excitability by estrogens via membrane-initiated signaling. Mol Cell Endocrinol 2009, 308:17-25.

166. Teyler TJ, Vardaris RM, Lewis D, Rawitch AB: Gonadal steroids: effects on excitability of hippocampal pyramidal cells. Science 1980, 209:1017-1018.

167. Foy MR, Xu J, Xie X, Brinton RD, Thompson RF, Berger TW: 17beta-estradiol enhances NMDA receptor-mediated EPSPs and long-term potentiation. $J$ Neurophysiol 1999, 81:925-929.

168. Vouimba RM, Foy MR, Foy JG, Thompson RF: 17beta-estradiol suppresses expression of long-term depression in aged rats. Brain Res Bull 2000, 53:783-787.

169. Roepke TA, Xue C, Bosch MA, Scanlan TS, Kelly MJ, Rønnekleiv OK: Genes associated with membrane-initiated signaling of estrogen and energy homeostasis. Endocrinology 2008, 149:6113-6124.

170. Gu G, Rojo AA, Zee MC, Yu J, Simerly RB: Hormonal regulation of CREB phosphorylation in the anteroventral periventricular nucleus. J Neurosci 1996, 16:3035-3044.

171. Wagner EJ, Rønnekleiv OK, Kelly MJ: The noradrenergic inhibition of an apamin-sensitive, small-conductance Ca2+-activated $\mathrm{K}+$ channel in hypothalamic gamma-aminobutyric acid neurons: pharmacology, estrogen sensitivity, and relevance to the control of the reproductive axis. J Pharmacol Exp Ther 2001, 299:21-30. 
172. Kelly MJ, Ronnekleiv OK, Eskay RL: Identification of estrogen-respons-ive LHRH neurons in the guinea pig hypothalamus. Brain Res Bull 1984, 12:399-407.

173. Navarro CE, Saeed SA, Murdock C, Martinez-Fuentes AJ, Arora KK, Krsmanovic LZ, Catt KJ: Regulation of cyclic adenosine 3',5'-monophosphate signaling and pulsatile neurosecretion by Gi-coupled plasma mem-brane estrogen receptors in immortalized gonadotrophin-releasing hormone neurons. Mol Endocrinol 2003, 17:1792-1804.

174. Abe $\mathrm{H}$, Terasawa E: Firing pattern and rapid modulation of activity by estrogen in primate luteinizing hormone releasing hormone- 1 neurons. Endocrinology 2005, 146:4312-4320.

175. Abe H, Keen KL, Terasawa E: Rapid action of estrogens on intracellular calcium oscillations in primate luteinizing hormone-releasing hormone-1 neurons. Endocrinology 2008, 149:1155-1162.

176. Morales A, Gonzalez M, Marin R, Diaz M, Alonso R: Estrogen inhibition of norepinephrine responsiveness is initiated at the plasma membrane of GnRH-producing GT1-7 cells. J Endocrinol 2007, 194:193-200.

177. Kow LM, Pfaff DW: The membrane actions of estrogens can potentiate their lordosis behavior-facilitating genomic actions. Proc Natl Acad Sci USA 2004, 101:12354-12357.

178. Micevych $P$, Dominguez R: Membrane estradiol signaling in the brain. Front Neuroendocrinol 2009, 30:315-327.

179. Peng HY, Chen GD, Tung KC, Chien YW, Lai CY, Hsieh MC, Chiu CH, Lai CH, Lee SD, Lin TB: Estrogen-dependent facilitation on spinal reflex potentiation involves the Cdk5/ERK1/2/NR2B cascade in anesthetized rats. Am J Physiol Endocrinol Metab 2009, 297:E416-426.

180. Wong JK, Le HH, Zsarnovszky A, Belcher SM: Estrogens and ICl182,780 (Faslodex) modulate mitosis and cell death in immature cerebellar neurons via rapid activation of $\mathrm{p} 44 / \mathrm{p} 42$ mitogen-activated protein kinase. $J$ Neurosci 2003, 23:4984-4995.

181. Alyea RA, Watson CS: Nongenomic mechanisms of physiological estrogen-mediated dopamine efflux. BMC Neurosci 2009, 10:59.

182. Lømo T: The discovery of long-term potentiation. Philos Trans $R$ Soc Lond B Biol Sci 2003, 358:617-620.

183. Otto T, Eichenbaum H, Wiener SI, Wible CG: Learning-related patterns of CA1 spike trains parallel stimulation parameters optimal for inducing hippocampal long-term potentiation. Hippocampus 1991, 1:181-192.

184. Abraham WC, Logan B, Greenwood JM, Dragunow M: Induction and experience-dependent consolidation of stable long-term potentiation lasting months in the hippocampus. J Neurosci 2002, 22:9626-9634.

185. Blitzer RD, lyengar R, Landau EM: Postsynaptic signaling networks: cellular cogwheels underlying long-term plasticity. Biol Psychiatry 2005, 57:113-119.

186. Blake JF, Brown MW, Collingridge GL: CNQX blocks acidic amino acid induced depolarizations and synaptic components mediated by nonNMDA receptors in rathippocampal slices. Neurosci Lett 1988, 89:182-186.

187. Andreasen M, Lambert JD, Jensen MS: Effects of new non-N-methyl-Daspartate antagonists on synaptic transmission in the in vitro rat hippocampus. J Physiol 1989, 414:317-336.

188. Davies SN, Collingridge GL: Role of excitatory amino acid receptors in synaptic transmission in area CA1 of rat hippocampus. Proc $R$ Soc Lond $B$ Biol Sci 1989, 236:373-384.

189. Lynch GS, Dunwiddie T, Gribkoff V: Heterosynaptic depression: a postsynaptic correlate of long-term potentiation. Nature 1977, 266:737-739.

190. Dudek SM, Bear MF: Homosynaptic long-term depression in area CA1 of hippocampus and effects of N-methyl-D-aspartate receptor blockade. Proc Natl Acad Sci USA 1992, 89:4363-4367.

191. Mulkey RM, Malenka RC: Mechanisms underlying induction of homosynaptic long-term depression in area CA1 of the hippocampus. Neuron 1992, 9:967-975.

192. Kemp N, McQueen J, Faulkes S, Bashir Zl: Different forms of LTD in the CA1 regoin of the hippocampus: role of age and stimulus protocol. Eur $J$ Neurosci 2000, 12:360-366.

193. Staubli UV, Ji ZX: The induction of homo- vs. heterosynaptic LTD in area CA1 of hippocampal slices from adult rats. Brain Res 1996, 714:169-176.

194. Kemp N, Bashir Zl: NMDA receptor-dependent and -independent longterm depression in the CA1 region of the adult rat hippocampus in vitro. Neuropharmacology 1997, 36:397-399.

195. Berretta N, Cherubini E: A novel form of long-term depression in the CA1 area of the adult rat hippocampus independent of glutamate receptors activation. Eur J Neurosci 1998, 10:2957-2963.
196. Cho K, Kemp N, Noel J, Aggleton JP, Brown MW, Bashir Zl: A new form of long-term depression in the perirhinal cortex. Nat Neurosci 2000, 3:150-156.

197. Lynch G, Kessler M, Halpain S, Baudry M: Biochemical effects of highfrequency synaptic activity studied with in vitro slices. Fed Proc 1983 42:2886-289.

198. Lisman JA: Mechanism for the Hebb and the anti-Hebb processes underlying learning and memory. Proc Natl Acad Sci USA 1989, 86:9574-9578

199. Bortolotto ZA, Collingridge $G L$ : A role for protein kinase $C$ in a form of metaplasticity that regulates the induction of long-term potentiation at CA1 synapses of the adult rat hippocampus. Eur J Neurosci 2000, 2:4055-4062

200. Colledge M, Dean RA, Scott GK, Langeberg LK, Huganir RL, Scott JD: Targeting of PKA to glutamate receptors through a MAGUK-AKAP complex. Neuron 2000, 27:107-119.

201. Esteban JA, Shi SH, Wilson C, Nuriya M, Huganir RL, Malinow R: PKA phosphorylation of AMPA receptor subunits controls synaptic trafficking underlying plasticity. Nat Neurosci 2003, 6:136-143.

202. McDonald BJ, Chung HJ, Huganir RL: Identification of protein kinase C phosphorylation sites within the AMPA receptor GluR2 subunit. Neuropharmacology 2001, 41:672-679.

203. Dickinson BA, Jo J, Seok H, Son GH, Whitcomb DJ, Davies CH, Sheng M, Collingridge $G L$, Cho K: A novel mechanism of hippocampal LTD involving muscarinic receptor-triggered interactions between AMPARs, GRIP and liprin-alpha. Mol Brain 2009, 2:18.

204. Kim JJ, Foy MR, Thompson RF: Behavioral stress modifies hippocampal plasticity through N-methyl-D-aspartate receptor activation. Proc Natl Acad Sci USA 1996, 93:4750-4753.

205. Rowan MJ, Anwyl R, Xu L: Stress and long-term synaptic depression. Mol Psychiatry 1998, 3:472-474.

206. Avital A, Segal M, Richter-Levin G: Contrasting roles of corticosteroid receptors in hippocampal plasticity. J Neurosci 2006, 26:9130-9134.

207. Pérez-Otaño I, Ehlers MD: Learning from NMDA receptor trafficking: clues to the development and maturation of glutamatergic synapses. Neurosignals 2004, 13:175-189.

208. Flint AC, Maisch US, Weishaupt JH, Kriegstein AR, Monyer H: NR2A subunit expression shortens NMDA receptor synaptic currents in developing neocortex. J Neurosci 1997, 17:2469-2476.

209. Cull-Candy S, Brickley S, Farrant M: NMDA receptor subunits: diversity, development and disease. Curr Opin Neurobiol 2001, 11:327-335.

210. Zhuo M: Plasticity of NMDA receptor NR2B subunit in memory and chronic pain. Mol Brain 2009, 2:4.

211. Wenzel A, Fritschy JM, Mohler H, Benke D: NMDA receptor heterogen-eity during postnatal development of the rat brain: differential expression of the NR2A, NR2B, and NR2C subunit proteins. J Neurochem 1997, 68:469-478.

212. Wenzel $A$, Villa $M$, Mohler $H$, Benke D: Developmental and regional expression of NMDA receptor subtypes containing the NR2D subunit in rat brain. J Neurochem 1996, 66:1240-1248.

213. Barria A, Malinow R: NMDA receptor subunit composition controls synaptic plasticity by regulating binding to CaMKII. Neuron 2005, 48:289-301.

214. Zhao J, Peng $Y, X u Z$, Chen RQ, Gu QH, Chen Z, Lu W: Synaptic metaplasticity through NMDA receptor lateral diffusion. J Neurosci 2008, 28:3060-3070

215. Greger $\mathrm{IH}$, Esteban JA: AMPA receptor biogenesis and trafficking. Curr Opin Neurobiol 2007, 17:289-297.

216. Pellegrini-Giampietro DE, Bennett MV, Zukin RS: Are Ca(2+)-permeable kainate/AMPA receptors more abundant in immature brain?. Neurosci Lett 1992, 144:65-69.

217. Arai Y, Mizuguchi M, Takashima S: Developmental changes of glutamate receptors in the rat cerebral cortex and hippocampus. Anat Embryol (Berl) 1997, 195:65-70.

218. Greger $I H$, Khatri $L$, Kong X, Ziff EB: AMPA receptor tetramerization ismediated by Q/R editing. Neuron 2003, 40:763-774.

219. Shi S, Hayashi Y, Esteban JA, Malinow R: Subunit-specific rules govern-ing AMPA receptor trafficking to synapses in hippocampal pyramidal neurons. Cell 2001, 105:331-343.

220. Esteban JA: AMPA receptor trafficking: a road map for synaptic plasticity. Mol Interv 2003, 3:375-385. 
221. Schlager MA, Hoogenraad CC: Basic mechanisms for recognition and transport of synaptic cargos. Mol Brain 2009, 2:25.

222. Jang MK, Mierke DF, Russek SJ, Farb DH: A steroid-modulatory domain on NR2B controls N-methyl-D-aspartate receptor proton sensitivity. Proc Natl Acad Sci USA 2004, 101:8198-8203.

doi:10.1186/1756-6606-3-2

Cite this article as: Riedemann et al: Corticosteroids: way upstream. Molecular Brain 2010 3:2.

Submit your next manuscript to BioMed Central and take full advantage of:

- Convenient online submission

- Thorough peer review

- No space constraints or color figure charges

- Immediate publication on acceptance

- Inclusion in PubMed, CAS, Scopus and Google Scholar

- Research which is freely available for redistribution

Submit your manuscript at www.biomedcentral.com/submit
C Biomed Central 